\title{
Mixed-Mode Third-Order Quadrature Oscillator Based on Single MCCFTA
}

\author{
Khachen KHAW-NGAM ${ }^{1}$, Montree KUMNGERN ${ }^{1}$, Fabian KHATEB $^{2,3}$ \\ ${ }^{1}$ Faculty of Engineering, King Mongkut's Institute of Technology Ladkrabang, Bangkok 10520, Thailand \\ ${ }^{2}$ Department of Microelectronics, Brno University of Technology, Technická 10, Brno, Czech Republic \\ ${ }^{3}$ Faculty of Biomedical Engineering, Czech Technical University in Prague, nám. Sítná 3105, Kladno, Czech Republic
}

kkmontre@gmail.com,khateb@feec.vutbr.cz

Submitted September 25, 2016 / Accepted February 21, 2017

\begin{abstract}
This paper presents a new mixed-mode thirdorder quadrature oscillator based on new modified current-controlled current follower transconductance amplifier (MCCFTA). The proposed circuit employs one MCCFTA as active element and three grounded capacitors as passive components which is highly suitable for integrated circuit implementation. The condition and frequency of oscillations can be controlled orthogonally and electronically by adjusting the bias currents of the active device. The circuit provides four quadrature current outputs and two quadrature voltage outputs into one single topology, which can be classified as mixed-mode oscillator. In addition, four quadrature current output terminals possess high-impedance level which can be directly connected to the next stage without additional buffer circuits. The performance of the proposed structure has been verified through PSPICE simulators using $0.25 \mu \mathrm{m}$ CMOS process from TSMC and experimental results are also investigated.
\end{abstract}

\section{Keywords}

Third-order quadrature oscillator, mixed-mode oscillator, modified current-controlled current follower transconductance amplifier (MCCFTA)

\section{Introduction}

At present, current-mode technique is very interesting approach due to the fact that it is easy as operating of arithmetic such as addition and subtraction signals, multiplication and division signals by a constant signal and potential to operate at lower supply voltage compared their voltage-mode circuits [1]. Regarding to a current-mode building block, the current differencing transconductance amplifier (CDTA) [2] is a really current-mode active building block, due to its input and output signals are current forms. The structure of this device is consisted of a unity-gain current source controlled by the difference of two inputs and an output transconductance amplifier providing electronic tuning capability through its transconductance gain $\left(g_{m}\right)$. Therefore, CDTA is highly suitable for realizing current-mode analog signal processing and CDTA-based circuits can also reduce number of passive resistors.

A quadrature oscillator (QO) usually provides sinusoids having a phase difference of $90^{\circ}$ that is useful in communication and measurement systems such as quadrature mixers and single sideband generators for communication system [3], vector generators and selective voltmeters for measurements system [4]. Several QOs using CDTAs as active element have been proposed in the literature; see, for example [5-12]. However, some structures do not exploit the full capability of the CDTA where typically one of two input terminals of the CDTA is floated and not used [8-12]. Unfortunately, floating terminal may increase the area of chip when these CDTA-based QOs build as IC's forms and also may cause some noise injection into the monolithic circuit.

Recently, a new concept of active building block with one current input and two kinds of current outputs, the socalled "current follower transconductance amplifier (CFTA)", has been introduced [13]. This device is modified from an original CDTA by removing the negative terminal. When subtraction current circuit as input stage is absent, the structure of CFTA is simple. Compared with CDTA, the number of transistor used for CFTA is lesser. Therefore, several CFTA-based analog signal processing circuits are reported [14-19]. The CFTA has been already used to realize QOs [20-26]. They, in conjunction, exhibit high potential for bring drown the number of components. However, all structures are second-order QOs. This work focuses on the third-order QOs, which enjoys the requirement of QOs such as orthogonal adjustability and electronic tunability of the condition of oscillation (CO) and frequency of oscillation (FO), and uses grounded capacitors and minimum number of active elements. Because of highorder network the circuit provides better frequency response and quality, compared with lower-order network [27]. This mention has been expressed in [28] by mathematical formulation, especially, to confirm phase noise reduction. Compared with a second-order oscillator, the third-order oscillator (three-stage oscillator) also offers lower phase noise [29]. As a result, a number of third-order 
QOs based on different active building blocks have been proposed [30-52]. The early system using operational transconductance amplifier (OTA) [30] enjoys electronic tuning capability, but its $\mathrm{CO}$ and FO are not decoupled and difficult to control. The QOs using active building blocks such as operational amplifier [31], second-generation current conveyor (CCII) [32-34], differential voltage current conveyor (DVCC) [35], operational transresistance amplifier (OTRA) [36], [37], [50], offer orthogonal control of $\mathrm{CO}$ and $\mathrm{FO}$, but these structures lack the electronic tuning capability. A number of electronic-controlled third-order QOs have been reported using active building blocks such as current-controlled CCII (CCCII) [38], [39], current difference transconductance amplifier (CDTA) [40], [41], current-controlled CDTA (CCDTA) [42], current-controlled current conveyor transconductance amplifier (CCCTA) [43], [44], OTRA and MOS-C [45], DDCC and VDTA [46], [51], [52], differential voltage current conveyor transconductance amplifier (DVCCTA) [47]. They exhibit high potential for enjoying up the electronic tunability. However, they require an excessive number of active components and the structures are not compact. The thirdorder oscillator QO based on log-domain technique is proposed in [48]. However, this structure is suitable only in bipolar technology. The structure in [49] proposed thirdorder QO using a single current-controlled current conveyor transconductance amplifier (CCCCTA), but the circuit does not exploit the full capability of the CCTA when $\mathrm{y}$-terminal of CCTA is not used and attached to ground. Until now, there is no CCCFTA-third-order QO available in open literature.

Therefore, this paper presents a new mixed-mode third-order QO employing a modified current-controlled current follower transconductance amplifier (MCCFTA) and three grounded capacitors. The concept of MCCFTA is similar to conventional CFTA [13], except $f$-terminal provides parasitic resistance $R_{\mathrm{f}}$ that can be controlled by the bias current [53]. Identical $z$-copy terminal can be obtained using current-mirrors [13] and connecting transconductance amplifiers in parallels connection are available [54], [55]. Thus, MCCFCTA is an active building block that provides the possibility for utilizing its resistance simulating element and its transconductance gains that can be electronically controlled through adjusting the bias currents. Therefore we have input parasitic resistance and transconductance gains (TAs) into a single MCCFTA for realizing a third-order QO with orthogonal control of the $\mathrm{CO}$ and FO. The proposed structure provides four quadrature current outputs and two quadrature voltage outputs. PSPICE simulation results are given to confirm the performance of the proposed structure. The comparison between the proposed third-order $\mathrm{QO}$ and previously third-order QOs is expressed as Tab. 1.

\section{Proposed Circuit}

The circuit symbol and the equivalent circuit of the MCCFTA are shown in Fig. 1 and CMOS implementation of MCCFTA is shown Fig. 2. The ideal port relations of Fig. 1 can be expressed by

$$
\left(\begin{array}{l}
I_{z 1} \\
I_{z 2} \\
I_{z c} \\
V_{f} \\
I_{x 1} \\
I_{x 2}
\end{array}\right)=\left(\begin{array}{cccccc}
1 & 0 & 0 & 0 & 0 & 0 \\
1 & 0 & 0 & 0 & 0 & 0 \\
1 & 0 & 0 & 0 & 0 & 0 \\
R_{f} & 0 & 0 & 0 & 0 & 0 \\
0 & \pm g_{m 1} & 0 & 0 & 0 & 0 \\
0 & 0 & \pm g_{m 2} & 0 & 0 & 0
\end{array}\right)\left(\begin{array}{c}
I_{f} \\
V_{z 1} \\
V_{z 2} \\
V_{z c} \\
V_{x 1} \\
V_{x 2}
\end{array}\right)
$$

where $R_{f}$ is the parasitic resistance at $f$-terminal and $g_{m 1}$ and $g_{m 2}$ are two TAs. The $\mathrm{z}_{1^{-}}, \mathrm{x}_{1}$-terminals and $g_{m 1}$ are existing terminals and TA of conventional CCFTA [50]. The $\mathrm{z}_{2-}$ and $\mathrm{z}_{\mathrm{c}}$-terminals are the $\mathrm{z}$-copy terminals [13] of CCFTA that can be obtained by adding current mirrors in conventional CCFTA. By cascading $g_{m 2}$ in parallel connection, $\mathrm{x}_{2^{-}}$ terminal in CCFTA can be obtained and hence the name MCCFTA. It should be noted that connecting $n$ TAs in parallel connection of MCCFTA is also possible. From the CMOS implementation of MCCFTA in Fig. 2, assuming that transistors $\mathrm{M}_{1}$ to $\mathrm{M}_{4}$ are matched and operated in saturation regions, the parasitic resistance at $\mathrm{f}$-terminal $\left(R_{\mathrm{f}}\right)$ can be given as

$$
R_{\mathrm{f}} \cong \frac{1}{\sqrt{8 \mu C_{\mathrm{ox}}\left(\frac{W}{L}\right) I_{\mathrm{b} 1}}}
$$

where $\mu$ is the carrier mobility, $C_{\mathrm{ox}}$ is the gate oxide capacitance per unit area, $W$ and $L$ are the channel width and length, respectively, of MOS transistor. From (2) and Fig. 2, the parasitic resistance $R_{\mathrm{f}}$ can be controlled by adjusting the bias current $I_{\mathrm{b}}$. This property makes it different from a conventional CFTA [13].

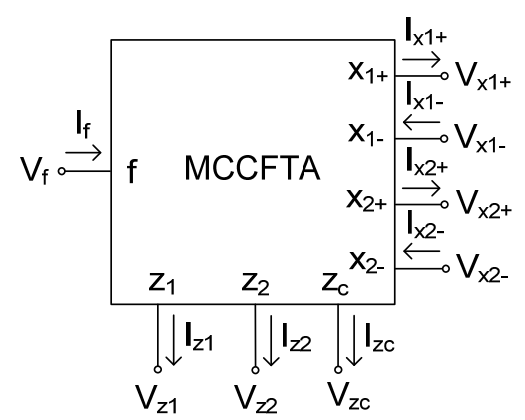

(a)

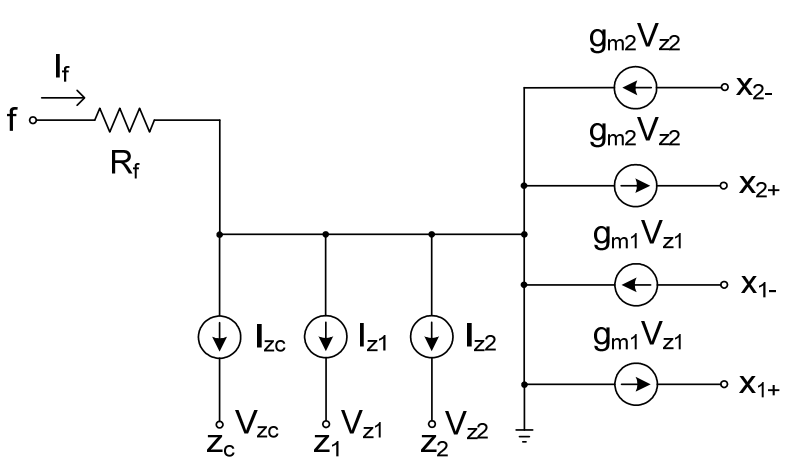

(b)

Fig. 1. MCCFTA: (a) electrical symbol, (b) equivalent circuit. 


\begin{tabular}{|c|c|c|c|c|c|c|c|c|c|c|c|c|c|c|c|c|c|c|c|c|c|c|c|}
\hline 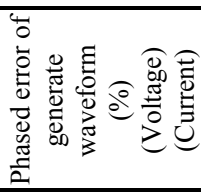 & 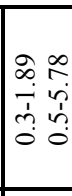 & ' & ' & ' & 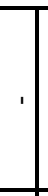 & & ' & & & & & & ' & & & & & $\begin{array}{l}+ \\
0 \\
\vdots\end{array}$ & & ' & & ' & \\
\hline 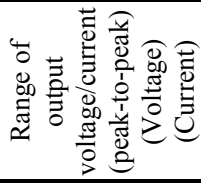 & \begin{tabular}{|ll} 
& \\
$\vdots$ & $\vdots$ \\
8 & 8 \\
0 & 0 \\
1 & 0 \\
0 & 0 \\
0 & 0 \\
\end{tabular} & ' & ' & ' & ' & & ' & & & ' & & & ' & & & ' & ' & ' & & ' & & & \\
\hline 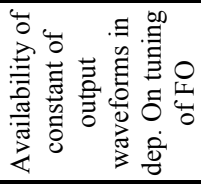 & z̊ & z) & ż & ż & z) & $\stackrel{2}{z}$ & z) & z) & ż & $\stackrel{z}{z}$ & z) & z & z) & z) & z) & Z) & z & ż & $\stackrel{0}{z}$ & $\stackrel{2}{z}$ & z & ż & $\stackrel{\circ}{z}$ \\
\hline 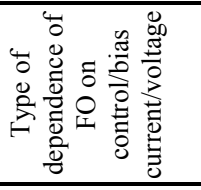 & 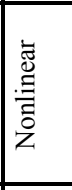 & 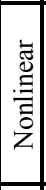 & 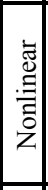 & 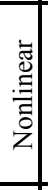 & 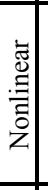 & 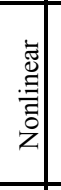 & 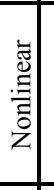 & 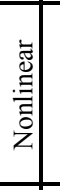 & 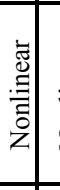 & 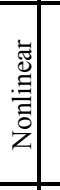 & 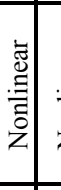 & 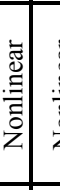 & 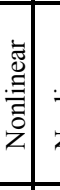 & 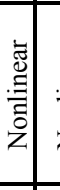 & 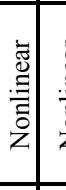 & 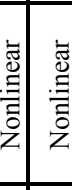 & 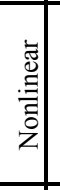 & 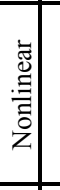 & 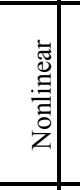 & 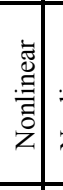 & 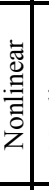 & 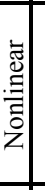 & 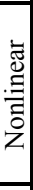 \\
\hline 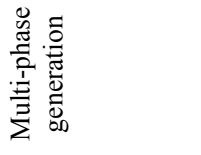 & $\stackrel{\infty}{\circlearrowright}$ & $\overbrace{}^{0}$ & $z$ & z) & z) & $\stackrel{0}{0}$ & $\stackrel{0}{>}$ & $z$ & ż & $\stackrel{0}{\infty}$ & $\stackrel{0}{\nu}$ & $z$ & $z$ & $z$ & z) & ż & z & $\stackrel{0}{2}$ & $\stackrel{s}{\sigma}$ & 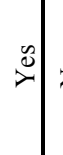 & $\stackrel{8}{z}$ & z & $z$ \\
\hline 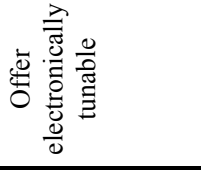 & $\stackrel{\infty}{\infty}$ & $\stackrel{\infty}{\infty}$ & $z$ & $\stackrel{0}{z}$ & z) & z) & z & z) & ż & $\stackrel{\infty}{\infty}$ & $\stackrel{0}{2}$ & $\stackrel{0}{0}$ & 2 & $\stackrel{0}{2}$ & $\stackrel{\infty}{\infty}$ & $\stackrel{2}{2}$ & $\overbrace{}^{\infty}$ & z) & $\stackrel{0}{\nu}$ & $\stackrel{0}{2}$ & z & $\stackrel{0}{>}$ & $\stackrel{\tilde{s}}{\nu}$ \\
\hline 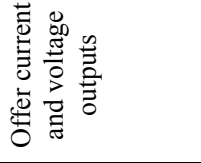 & 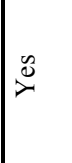 & z) & ż & $\stackrel{0}{z}$ & $\overbrace{}^{0}$ & $\stackrel{0}{0}$ & $\stackrel{0}{2}$ & $z$ & z) & $\stackrel{2}{z}$ & $\stackrel{0}{2}$ & z & $\stackrel{0}{>}$ & $\stackrel{0}{2}$ & $\stackrel{0}{z}$ & ż & z & $\underbrace{0}$ & $\stackrel{0}{z}$ & $\underbrace{\infty}$ & $\stackrel{2}{z}$ & $z$ & 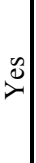 \\
\hline 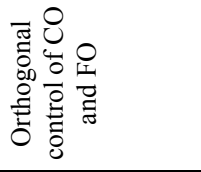 & $\stackrel{0}{\check{\nu}}$ & $\stackrel{0}{>}$ & $\stackrel{0}{<}$ & $\stackrel{0}{0}$ & $\stackrel{0}{0}$ & $\stackrel{0}{0}$ & $\stackrel{0}{\nu}$ & $\underbrace{2}$ & $\stackrel{\circlearrowright}{\Delta}$ & 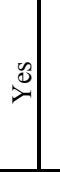 & 2 & $\stackrel{0}{\succ}$ & $\stackrel{0}{\overrightarrow{0}}$ & $\stackrel{0}{2}$ & $\stackrel{\Delta}{\Delta}$ & 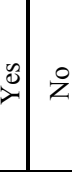 & $\stackrel{0}{2}$ & $\stackrel{0}{\nu}$ & $\stackrel{8}{0}$ & $\stackrel{0}{2}$ & $\stackrel{0}{2}$ & $\stackrel{0}{>}$ & $\stackrel{0}{\overrightarrow{0}}$ \\
\hline 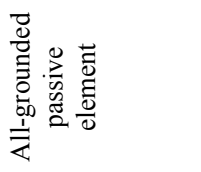 & 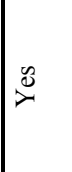 & $\stackrel{0}{0}$ & 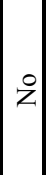 & $\stackrel{0}{0}$ & z) & $\stackrel{0}{0}$ & z & $z$ & z & $\stackrel{\infty}{\infty}$ & $\stackrel{0}{2}$ & $\stackrel{0}{0}$ & $\stackrel{0}{2}$ & $\stackrel{0}{2}$ & $\stackrel{\infty}{\stackrel{0}{0}}$ & $\stackrel{2}{8}$ & $\overbrace{}^{\infty}$ & 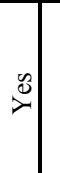 & $\stackrel{0}{0}$ & $\stackrel{0}{\infty}$ & z & $\stackrel{0}{2}$ & $\stackrel{0}{\Delta}$ \\
\hline 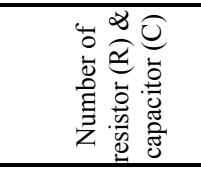 & $\begin{array}{l}0 \\
\dot{m}\end{array}$ & $\begin{array}{l}\dot{m} \\
\dot{m}\end{array}$ & $\begin{array}{c}r \\
n \\
0 \\
0 \\
m \\
m\end{array}$ & \begin{tabular}{l}
\multicolumn{1}{c}{} \\
$n$ \\
$ن$ \\
$n$ \\
$n$
\end{tabular} & 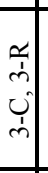 & 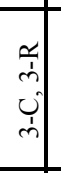 & \begin{tabular}{l}
\multicolumn{1}{c}{} \\
\\
0 \\
1 \\
$n$
\end{tabular} & 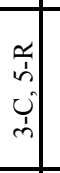 & 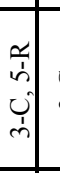 & $\begin{array}{l}0 \\
\end{array}$ & $\begin{array}{l}0 \\
\grave{m}\end{array}$ & $\begin{array}{l}0 \\
\end{array}$ & $\begin{array}{l}0 \\
\stackrel{m}{\prime}\end{array}$ & $\begin{array}{l}0 \\
\end{array}$ & $\begin{array}{l}0 \\
m \\
m\end{array}$ & 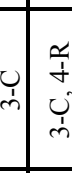 & \begin{tabular}{l}
\multicolumn{1}{c}{} \\
-1 \\
$ن$ \\
1 \\
$n$
\end{tabular} & 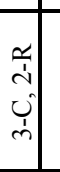 & $\begin{array}{l}0 \\
m\end{array}$ & $\begin{array}{l}\underbrace{}_{1} \\
m\end{array}$ & 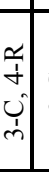 & ن & $\begin{array}{l}\dot{1} \\
\dot{m}\end{array}$ \\
\hline 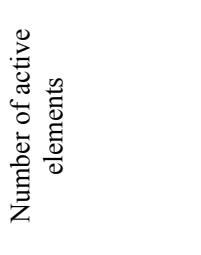 & 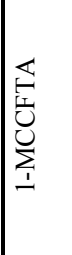 & 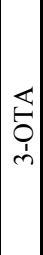 & 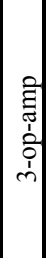 & $\begin{array}{l}0 \\
己 \\
0 \\
n\end{array}$ & 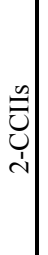 & 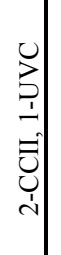 & $\begin{array}{l}0 \\
ن \\
> \\
\text { nे }\end{array}$ & 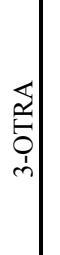 & 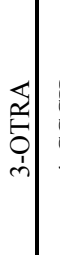 & 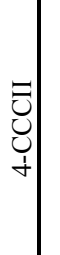 & 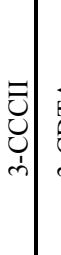 & 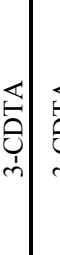 & 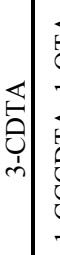 & 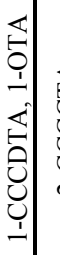 & 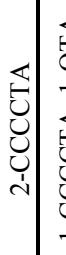 & 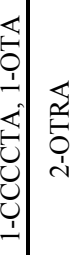 & 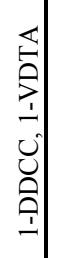 & 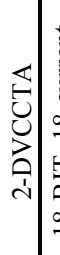 & 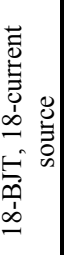 & $\begin{array}{l}\leq \\
0 \\
0 \\
0 \\
0 \\
-\end{array}$ & 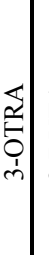 & 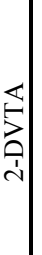 & 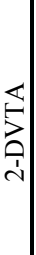 \\
\hline & 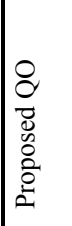 & 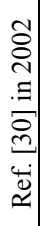 & 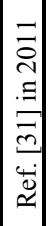 & 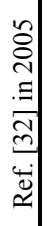 & 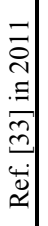 & 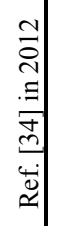 & 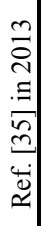 & 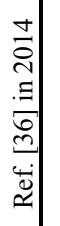 & 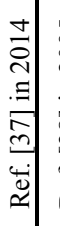 & 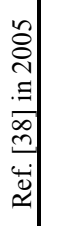 & 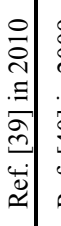 & 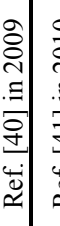 & 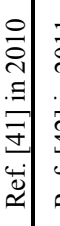 & 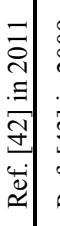 & 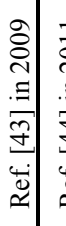 & 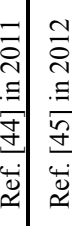 & 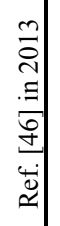 & 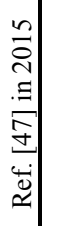 & 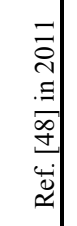 & 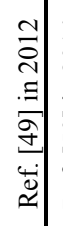 & 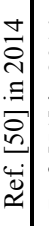 & 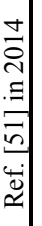 & 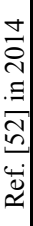 \\
\hline
\end{tabular}

Tab. 1. Comparison of the proposed third-order QO with those of previous third-order QOs. 


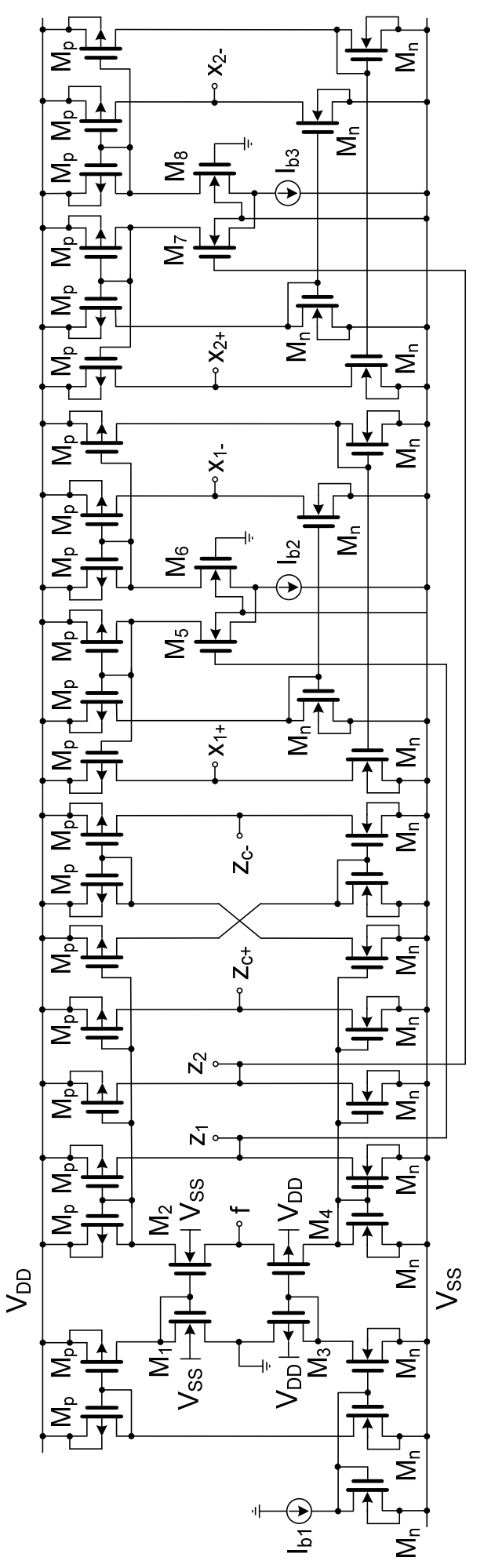

Fig. 2. CMOS implementation for MCCFTA.

The transconductance gains $g_{m 1}$ and $g_{m 2}$ can be obtained by assuming the transistors $\mathrm{M}_{5}-\mathrm{M}_{6}$ and $\mathrm{M}_{7}-\mathrm{M}_{8}$ are matched and operated in saturation region, $g_{m 1}$ and $g_{m 2}$ of MCCFTA can be expressed, respectively, as

$$
g_{m 1}=\sqrt{\mu C_{\mathrm{ox}}\left(\frac{W}{L}\right) I_{\mathrm{b} 2}},
$$

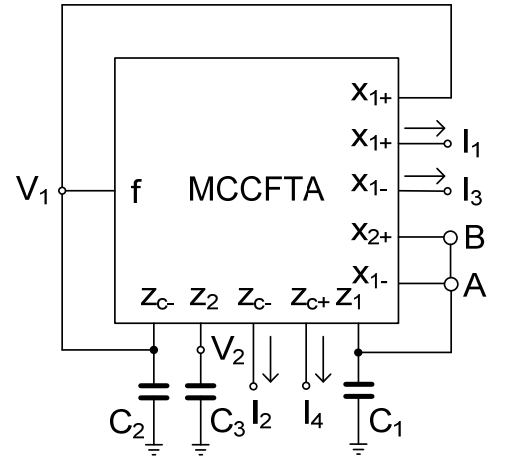

(a)

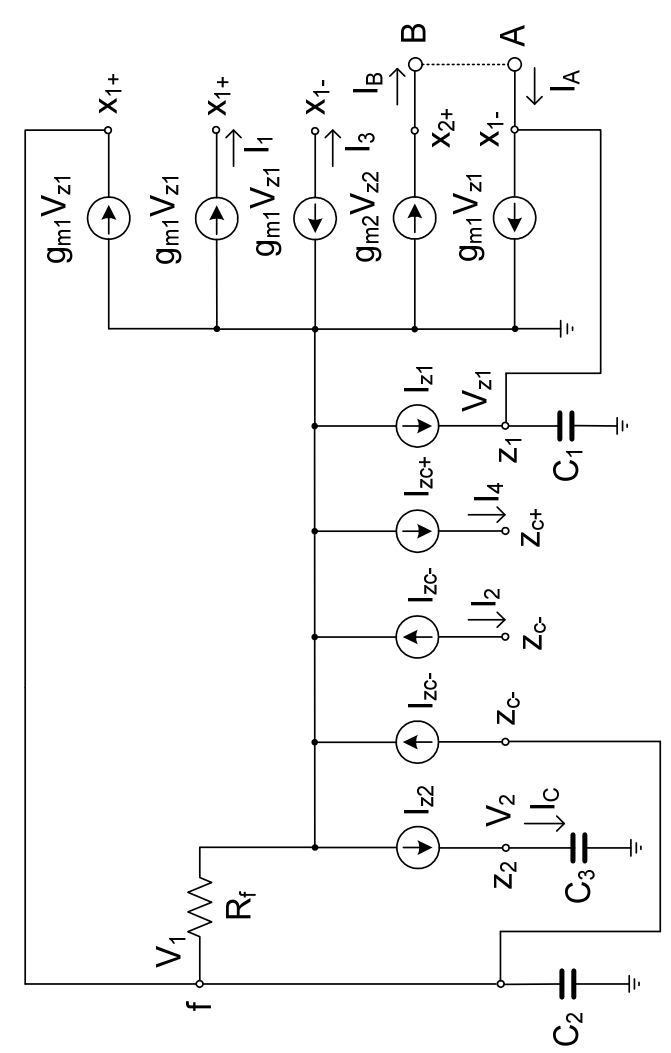

(b)

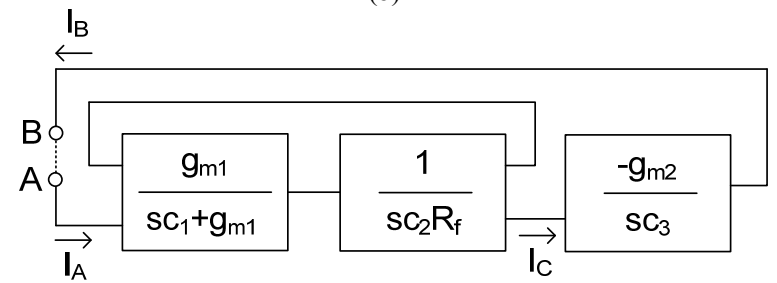

(c)

Fig. 3. Proposed third-order QO: (a) circuit symbol, (b) equivalent circuit, (c) block diagram.

$$
g_{m 2}=\sqrt{\mu C_{\mathrm{ox}}\left(\frac{W}{L}\right) I_{\mathrm{b} 3}} .
$$

From (3) and (4), transconductance gains $g_{m 1}$ and $g_{m 2}$ can be controlled by adjusting the bias currents $I_{\mathrm{b} 2}$ and $I_{\mathrm{b} 3}$, respectively. The $\mathrm{z}_{\mathrm{c}^{-}}$and $\mathrm{z}_{\mathrm{c}^{-}}$-terminals (z-copy CFTA) can be obtained by adding current mirrors and cross couple current mirrors in CCFTA as shown in Fig. 2. 
The third-order oscillator can be realized from the third-order polynomial equation as

$$
N(s)=a_{0} s^{3}+a_{1} s^{3}+a_{2} s+a_{3} .
$$

Letting $N(s)=0$ and $s=\mathrm{j} \omega$, (5) becomes the third-order oscillator characteristic as

$$
0=-j \omega^{3} a_{0}-\omega^{2} a_{1}+j \omega a_{2}+a_{3} .
$$

Considering the coefficient of real and imaginary parts, we have:

$$
\begin{gathered}
a_{3}-\omega^{2} a_{1}=0, \\
\omega a_{2}-\omega^{3} a_{0}=0 .
\end{gathered}
$$

From (7) and (8), the $\mathrm{CO}$ and $\mathrm{FO}$ can be given respectively [30] by

$$
\begin{gathered}
a_{0} a_{3}=a_{1} a_{2}, \\
\omega=\sqrt{\frac{a_{3}}{a_{1}}}=\sqrt{\frac{a_{2}}{a_{0}}} .
\end{gathered}
$$

The proposed mixed-mode third-order QO is shown in Fig. 3. It is continuously developed from the circuit proposed in [56] by expanding text, simulation results and adding experimental results. The circuit is consisted of only one MCCFTA and three grounded capacitors. The use of grounded capacitors makes the proposed circuit ideal for IC implementation [57]. The characteristic equation of proposed circuit can be expressed using Fig. 3(b). To easy following, the proposed QO can be shown as block diagram in Fig. 3(c). Considering currents $I_{\mathrm{A}}$ and $I_{\mathrm{C}}$, current transfer function between $I_{\mathrm{C}}$ and $I_{\mathrm{A}}$ can be given by

$$
\frac{I_{\mathrm{C}}}{I_{\mathrm{A}}}=\frac{g_{m 1}}{s^{2} C_{1} C_{2} R_{f}+s C_{2} g_{m 1} R_{f}+g_{m 1}} .
$$

In addition, considering currents $I_{\mathrm{B}}$ and $I_{\mathrm{A}}$, current transfer function can be given by

$$
\frac{I_{\mathrm{B}}}{I_{\mathrm{A}}}=\frac{-g_{m 1} g_{m 2}}{s^{3} C_{1} C_{2} C_{3} R_{f}+s^{2} C_{2} C_{3} g_{m 1} R_{f}+s C_{3} g_{m 1}} .
$$

Letting $I_{\mathrm{B}} / I_{\mathrm{A}}=1$ (nodes $\mathrm{A}$ and $\mathrm{B}$ are closed), the characteristic equation of proposed QO in Fig. 3 can be expressed as

$$
s^{3}+\frac{g_{m 1}}{C_{1}} s^{2}+s \frac{g_{m 1}}{C_{1} C_{2} R_{f}}+\frac{g_{m 1} g_{m 2}}{C_{1} C_{2} C_{3} R_{f}}=0 .
$$

Compared with (5), the coefficients can be expressed as:

$$
\begin{gathered}
a_{0}=1, \\
a_{1}=\frac{g_{m 1}}{C_{1}}, \\
a_{2}=\frac{g_{m 1}}{C_{1} C_{2} R_{f}}, \\
a_{3}=\frac{g_{m 1} g_{m 2}}{C_{1} C_{2} C_{3} R_{\mathrm{f}}} .
\end{gathered}
$$

According to (9) and (10), the CO and FO are obtained, respectively, by

$$
\begin{gathered}
g_{m 2}=\frac{g_{m 1} C_{3}}{C_{1}}, \\
\omega_{o}=\sqrt{\frac{g_{m 1}}{C_{1} C_{2} R_{f}}} .
\end{gathered}
$$

It is evident from (14) and (15) that the $\mathrm{CO}$ can be controlled using $g_{m 2}$ by keeping $C_{1}=C_{3}$ and $g_{m 1}$ constant and the FO can be controlled by $R_{f}$ by keeping $C_{1}=C_{2}$ $\left(C_{1}=C_{2}=C_{3}\right)$ and $g_{m 1}$ constant. Therefore, the $\mathrm{CO}$ and FO can be orthogonally controlled. From Fig. 3, the relationship between $I_{2}$ and $I_{1}$ can be expressed by

$$
\frac{I_{2}}{I_{1}}=\frac{1}{s C_{2} R_{f}}
$$

while the relationship between voltages $V_{1}$ and $V_{2}$ can be expressed as

$$
\frac{V_{2}}{V_{1}}=\frac{1}{s C_{3} g_{m 2}}
$$

where the phase difference is $\phi=\pi / 2$. This guarantees that the proposed QO provides the quadrature output currents $I_{1}$ and $I_{2}$ and quadrature output voltages $V_{1}$ and $V_{2}$. Also the uses of multiple-output MCCFTA that provides inversion of the output currents, thus it leads to $I_{3}=-I_{1}$ and $I_{4}=-I_{2}$. Moreover, all current output terminals are at high impedance of MCCFTA, thus ensuring insensitive current outputs that require no additional current followers to be sensed. However, if quadrature output voltages $V_{1}$ and $V_{2}$ are used, loads cannot be connected directly, the buffer circuit is needed. This problem can be solved easily using voltage follower circuit.

\section{Non-Ideal Analysis}

To consider the non-ideal effect of a MCCFTA by taking the non-idealities of the MCCFTA into account, the relationship of the terminal voltages and currents can be rewritten as

$$
\left(\begin{array}{l}
I_{z 1} \\
I_{z 2} \\
I_{z c} \\
V_{f} \\
I_{x 1} \\
I_{x 2}
\end{array}\right)=\left(\begin{array}{cccccc}
\alpha_{1} & 0 & 0 & 0 & 0 & 0 \\
\alpha_{2} & 0 & 0 & 0 & 0 & 0 \\
\alpha_{c} & 0 & 0 & 0 & 0 & 0 \\
R_{f} & 0 & 0 & 0 & 0 & 0 \\
0 & \pm g_{m 1} & 0 & 0 & 0 & 0 \\
0 & 0 & \pm g_{m 2} & 0 & 0 & 0
\end{array}\right)\left(\begin{array}{l}
I_{f} \\
V_{z 1} \\
V_{z 2} \\
V_{z c} \\
V_{x 1} \\
V_{x 2}
\end{array}\right)
$$

where $\alpha_{1}=1-\varepsilon_{i 1}$ and $\varepsilon_{i 1}\left(\varepsilon_{i 1}<<1\right)$ is the current tracking error from f-terminal to $\mathrm{z}_{1}$-terminal, $\alpha_{2}=1-\varepsilon_{\mathrm{i} 2}$ and $\varepsilon_{\mathrm{i} 2}\left(\varepsilon_{\mathrm{i} 2}<<1\right)$ is the current tracking error from f-terminal to $\mathrm{z}_{2}$-terminal and $\alpha_{\mathrm{c}}=1-\varepsilon_{\mathrm{ic}}$ and $\varepsilon_{\mathrm{ic}}\left(\varepsilon_{\mathrm{ic}}<<1\right)$ is the current tracking error from $\mathrm{f}$-terminal to $\mathrm{z}_{\mathrm{c}}$-terminal, $R_{f}$ is the parasitic resistances at f-terminal. At high-frequency operating, 


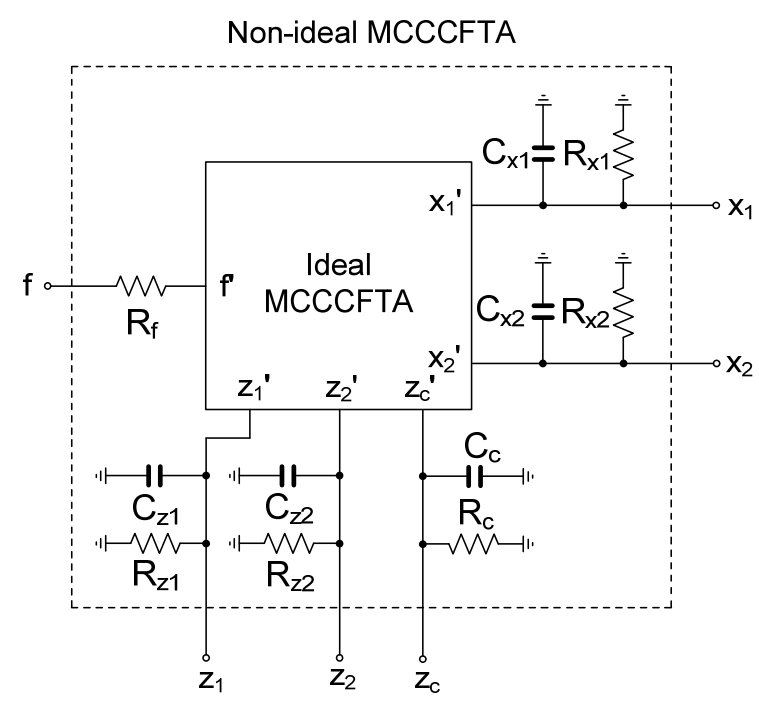

Fig. 4. Non-ideal of MCCFTA at high operating frequency.

non-ideal model of MCCFTA can be shown in Fig. 4. $R_{z 1}$, $R_{z 2}$ and $R_{z c}$ are respectively the high parasitic resistances at $\mathrm{z}_{1}-, \mathrm{z}_{2}-$ and $\mathrm{z}_{\mathrm{c}}$-terminals, $R_{x 1}$ and $R_{\mathrm{x} 2}$ are respectively the high parasitic resistances at $\mathrm{x}_{1}-$ and $\mathrm{x}_{2}$-terminals, $C_{\mathrm{z} 1}, C_{\mathrm{z} 2}$ and $C_{\mathrm{zc}}$ are respectively the low parasitic capacitances at $\mathrm{z}_{1}-, \mathrm{z}_{2}-$ and $\mathrm{z}_{\mathrm{c}}$-terminals and $C_{\mathrm{x} 1}$ and $C_{\mathrm{x} 2}$ are respectively the low parasitic capacitances at $\mathrm{x}_{1}$ - and $\mathrm{x}_{2}$-terminals.

Taking into account the non-ideal MCCFTA characteristics, current transfer function between $I_{\mathrm{B}}$ and $I_{\mathrm{A}}$ can be rewritten as

$\frac{I_{\mathrm{B}}}{I_{\mathrm{A}}}=$

$\frac{-Z_{1} Z_{2} Z_{3} g_{m 1} g_{m 2} \alpha_{1} \alpha_{2} \alpha_{c}}{\left(Z_{1} Z_{2} g_{m 1}+Z_{1} R_{f} g_{m 1}+Z_{2}+R_{f}+Z_{1} Z_{2} g_{m 1} \alpha_{1} \alpha_{c}-Z_{1} Z_{2} g_{m 1} \alpha_{1}-Z_{2} \alpha_{1}\right)}$

where

$$
\begin{gathered}
Z_{1}=\frac{R_{p 1}}{s C_{1}^{\prime} R_{p 1}+1}, \\
Z_{2}=\frac{R_{p 2}}{s C_{2}^{\prime} R_{p 2}+1}, \\
Z_{3}=\frac{R_{p 3}}{s C_{3}^{\prime} R_{p 3}+1}, \\
C_{1}^{\prime}=C_{1}\left\|C_{x 1-}\right\| C_{x 2+} \| C_{z}, \\
C_{2}^{\prime}=C_{2}\left\|C_{x 1+}\right\| C_{z c-}, \\
C_{3}^{\prime}=C_{3} \| C_{z 2}, \\
R_{p 1}=R_{x 1-}\left\|R_{x 2+}\right\| R_{z}, \\
R_{p 2}=R_{x 1+} \| R_{z c-}, \\
R_{p 3}=R_{z 2} .
\end{gathered}
$$

The modified characteristic equation of Fig. 3 can be rewritten as

$$
\begin{aligned}
& s^{3}+s^{2} \frac{g_{m 1}}{C_{1}^{\prime}}\left(\begin{array}{l}
1+\frac{1}{g_{m 1} R_{f}}+\frac{1}{g_{m 1} R_{p 2}}+\frac{1}{g_{m 1} R_{p 1}} \\
+\frac{C_{1}^{\prime}}{C_{3}^{\prime} g_{m 1} R_{p 3}}-\frac{\alpha_{1}}{g_{m 1} R_{f}}
\end{array}\right) \\
& +s \frac{g_{m 1}}{C_{1}^{\prime} C_{2}^{\prime} R_{f}}\left(\begin{array}{l}
1+\alpha_{1} \alpha_{c}+\frac{1}{g_{m 1} R_{p 1}}+\frac{R_{f}}{R_{p 2}}+\frac{C_{2}^{\prime} R_{f}}{C_{3}^{\prime} R_{p 3}} \\
+\frac{C_{1}^{\prime}}{C_{3}^{\prime} g_{m 1} R_{p 3}}+\frac{R_{f}}{g_{m 1} R_{p 1} R_{p 2}}+\frac{C_{1}^{\prime} R_{f}}{C_{3}^{\prime} g_{m 1} R_{p 2} R_{p 3}} \\
+\frac{C_{2}^{\prime} R_{f}}{C_{3}^{\prime} g_{m 1} R_{p 1} R_{p 3}}-\frac{\alpha_{1}}{g_{m 1} R_{p 1}}-\frac{\alpha_{1}}{g_{m 1} R_{p 1}}-\alpha_{1}
\end{array}\right) \\
& +\frac{g_{m 1} g_{m 2} \alpha_{1} \alpha_{2} \alpha_{c}}{C_{1}^{\prime} C_{2}^{\prime} C_{3}^{\prime} R_{f}}\left(\begin{array}{l}
1+\frac{1}{g_{m 1} g_{m 2} R_{p 1} R_{p 3} \alpha_{1} \alpha_{2} \alpha_{c}}+\frac{1}{g_{m 2} R_{p 3} \alpha_{2}} \\
+\frac{1}{g_{m 2} R_{p 3} \alpha_{1} \alpha_{2} \alpha_{c}}+\frac{R_{f}}{g_{m 2} R_{p 2} R_{p 3} \alpha_{1} \alpha_{2} \alpha_{c}} \\
+\frac{R_{f}}{g_{m 1} g_{m 2} R_{p 1} R_{p 2} R_{p 3} \alpha_{1} \alpha_{2} \alpha_{c}} \\
-\frac{1}{g_{m 1} g_{m 2} R_{p 1} R_{p 3} \alpha_{2} \alpha_{c}}-\frac{1}{g_{m 2} R_{p 3} \alpha_{2} \alpha_{c}}
\end{array}\right)
\end{aligned}
$$

Letting, parasitic parameters $R_{\mathrm{z}}, R_{\mathrm{c}}, R_{\mathrm{x}}$ are very high resistance values and $C_{z}, C_{c}, C_{c}$ are very low capacitance value, (20) can be approximated as

$$
s^{3}+s^{2} \frac{g_{m 1}}{C_{1}^{\prime}}+s \frac{g_{m 1}}{C_{1}^{\prime} C_{2}^{\prime} R_{f}}+\frac{g_{m 1} g_{m 2} \alpha_{1} \alpha_{2} \alpha_{c}}{C_{1}^{\prime} C_{2}^{\prime} C_{3}^{\prime} R_{f}}=0
$$

In this case, the $\mathrm{CO}$ and $\mathrm{FO}$ are modified, respectively, as:

$$
\begin{aligned}
& g_{m 2}=\frac{g_{m 1} C_{3}^{\prime}}{C_{1}^{\prime}} \alpha_{1} \alpha_{2} \alpha_{c}, \\
& \omega_{o}=\sqrt{\frac{g_{m 1} g_{m 2} \alpha_{1} \alpha_{2} \alpha_{c}}{C_{1}^{\prime} C_{2}^{\prime} C_{3}^{\prime} R_{f}}} .
\end{aligned}
$$

The various passive sensitivities of $\omega_{o}$ of the proposed QO can be obtained as

$$
\left.\begin{array}{r}
S_{g_{m 1}}^{\omega_{0}}=S_{g_{m 2}}^{\omega_{0}}=S_{\alpha_{1}}^{\omega_{0}}=S_{\alpha_{2}}^{\omega_{0}}=S_{\alpha_{3}}^{\omega_{0}}=0.5 \\
S_{R_{f}}^{\omega_{0}}=S_{C_{1}^{\prime}}^{\omega_{0}}=S_{C_{2}^{\prime}}^{\omega_{0}}=S_{C_{3}^{\prime}}^{\omega_{0}}=-0.5
\end{array}\right\}
$$

Thus, the proposed QO has low active and passive sensitivities.

\section{Simulation Results}

To verify the theoretical prediction of the proposed third-order QO, the circuit in Fig. 3 was simulated using PSPICE simulators and the MCCFTA in Fig. 2 was used. The model parameters for nMOS and pMOS transistors are taken from $0.25 \mu \mathrm{m}$ CMOS process from TSMC. The power supply was given as $\pm 1 \mathrm{~V}$. From Fig. 2, $I_{\mathrm{b} 1}$ was 
initially designed for $100 \mu \mathrm{A}$ while $I_{\mathrm{b} 2}$ and $I_{\mathrm{b} 3}$ were initially designed for $150 \mu \mathrm{A}$. Transistors around trans-linear loop $\left(\mathrm{M}_{1}\right.$ to $\left.\mathrm{M}_{4}\right)$ were designed to obtain $g_{m(\mathrm{nMOS})}=g_{m(\mathrm{pMOS})}$ and differential transistor pairs $\left(\mathrm{M}_{5}-\mathrm{M}_{6}\right.$ and $\left.\mathrm{M}_{7}-\mathrm{M}_{8}\right)$ were designed to obtain $g_{m(\text { total })}=\left(g_{m(\mathrm{M} 5)}+g_{m(\mathrm{M} 6)}\right) / 2$ or $g_{m(\text { total })}=$ $\left(g_{m(\mathrm{M} 7)}+g_{m(\mathrm{M} 8)}\right) / 2$. For $0.25 \mu \mathrm{m}$ CMOS process used in this case, $\left(\mu_{o} C_{\mathrm{ox}}\right)_{\mathrm{nMOS}}=242.2 \mu \mathrm{A} / \mathrm{V}^{2}$ and $\left(\mu_{o} C_{\mathrm{ox}}\right)_{\mathrm{pMOS}}=$ $51.8 \mu \mathrm{A} / \mathrm{V}^{2}, V_{\text {tho(nMos) }}=0.37 \mathrm{~V}$ and $V_{\text {tho(pMos })}=-0.49 \mathrm{~V}$ were given. Therefore, the aspect ratios of MOS transistors for MCCFTA in Fig. 3 were $W / L=5 \mu \mathrm{m} / 0.5 \mu \mathrm{m}$ for $\mathrm{M}_{1}$ $\mathrm{M}_{2}, W / L=15 \mu \mathrm{m} / 0.5 \mu \mathrm{m}$ for $\mathrm{M}_{3}-\mathrm{M}_{4}, W / L=5 \mu \mathrm{m} / 0.5 \mu \mathrm{m}$ for $\mathrm{M}_{5}-\mathrm{M}_{8}, W / L=5 \mu \mathrm{m} / 0.5 \mu \mathrm{m}$ for all $\mathrm{M}_{\mathrm{n}}$ transistors and $W / L=15 \mu \mathrm{m} / 0.5 \mu \mathrm{m}$ for all $\mathrm{M}_{\mathrm{p}}$ transistors. PSPICE simulations have verified that when $I_{\mathrm{b} 1}$ was varied from 1 to $100 \mu \mathrm{A}$, achieved $R_{f}$ was in the range of 12 to $2.19 \mathrm{k} \Omega$ as shown in Fig. 5 whereas $I_{\mathrm{b} 2}$ and $I_{\mathrm{b} 3}$ were varied from 5 to $150 \mu \mathrm{A}$, achieved $g_{m 1}$ and $g_{m 2}$ were in the range of 107 to $472 \mu \mathrm{A} / \mathrm{V}$ as shown in Fig. 6 . Both simulated $R_{f}-$ and $g_{m^{-}}$ value were compared with (2) and (3), respectively. Simulated performances of MCCFTA were summarized in Tab. 2.

The voltage outputs and current outputs were shown respectively in Figs. 7 and 8, when Fig. 3 was designed with the following values: $C_{1}=C_{2}=C_{3}=20 \mathrm{pF}, I_{\mathrm{b} 1}=$ $20 \mu \mathrm{A}, I_{\mathrm{b} 2}=80 \mu \mathrm{A}$ and $I_{\mathrm{b} 3}=75 \mu \mathrm{A}$. The $I_{\mathrm{b} 3}$-value was varied for $g_{m 2}$ so as to satisfy the CO in (14). In this case, $\left(R_{f} \approx 1 / g_{m 1}\right)$, each current output and each voltage output were almost equal of magnitude. The magnitudes of the quadrature signals will not be equaled in case of $R_{f}$ was varied $\left(R_{f} \neq 1 / g_{m 1}\right)$ in (15). For applications requiring equal magnitude quadrature outputs, additional amplifying circuits were needed. From Fig. 7, the simulated THD of $V_{1}$ and $V_{2}$ were about $0.26 \%$ and $0.17 \%$, respectively, the FO was $2.7 \mathrm{MHz}$. From Fig. 8, the simulated the FO was found to be $2.7 \mathrm{MHz}$, the results of the $I_{1}, I_{2}, I_{3}$ and $I_{4}$ total harmonic distortion (THD) analysis were obtained as $0.56 \%$, $0.37 \%, 0.85 \%$ and $0.38 \%$, respectively, and the power consumption was about $1.43 \mathrm{~mW}$. This low THD was obtained for the output signals $V_{1}, V_{2}, I_{1}, I_{2}, I_{3}$ and $I_{4}$ of $204 \mathrm{mV}_{\text {P-P }}, 198 \mathrm{mV}_{\text {P-P }}, 70 \mu \mathrm{A}_{\text {P-P }}, 70 \mu \mathrm{A}_{\text {P-P }}, 70 \mu \mathrm{A}_{\text {P-P }}$ and

\begin{tabular}{|l|c|}
\hline \multicolumn{1}{|c|}{ Parameters } & Value \\
\hline Technology & $0.25 \mu \mathrm{m}$ CMOS \\
\hline Power supply & $\pm 1 \mathrm{~V}$ \\
\hline $\mathrm{R}_{\mathrm{f}}\left(\mathrm{I}_{\mathrm{b}}=1-100 \mu \mathrm{A}\right)$ & 12 to $2.19 \mathrm{k} \Omega$ \\
\hline $\mathrm{g}_{\mathrm{m}}\left(\mathrm{I}_{\mathrm{b}}=5-150 \mu \mathrm{A}\right)$ & 107 to $472 \mu \mathrm{A} / \mathrm{V}$ \\
\hline Input and output range $\left(\mathrm{I}_{\mathrm{b}}=5-150 \mu \mathrm{A}\right)$ & \pm 40 to $\pm 250 \mathrm{mV}$ \\
\hline Bandwidth $(-3 \mathrm{~dB}) @ \mathrm{I}_{\mathrm{b} 1}=50 \mu \mathrm{A}$, & \\
$\mathrm{I}_{\mathrm{b} 2}=\mathrm{I}_{\mathrm{b} 3}=100 \mu \mathrm{A}$ & $42.84 \mathrm{MHz}$ \\
Current follower $\left(\mathrm{I}_{\mathrm{z}} / \mathrm{I}_{\mathrm{f}}\right)$ & $39.9 \mathrm{MHz}$ \\
Current follower $\left(\mathrm{I}_{\mathrm{x}} / \mathrm{I}_{\mathrm{f}}\right)\left(\mathrm{R}_{\mathrm{z}}=2.23 \mathrm{k} \Omega\right)$ & \\
\hline Current gain & 1.034 \\
$@ \mathrm{I}_{\mathrm{b} 1}=50 \mu \mathrm{A}, \mathrm{I}_{\mathrm{b} 2}=\mathrm{I}_{\mathrm{b} 3}=100 \mu \mathrm{A}$ & \\
$-\mathrm{I}_{\mathrm{z}} / \mathrm{I}_{\mathrm{f}}$ & \\
\hline Parasitic parameters & $116 \mathrm{k} \Omega, 25 \mathrm{fF}$ \\
$@ \mathrm{I}_{\mathrm{b} 1}=50 \mu \mathrm{A}, \mathrm{I}_{\mathrm{b} 2}=\mathrm{I}_{\mathrm{b} 3}=100 \mu \mathrm{A}$ & $96 \mathrm{k} \Omega, 25 \mathrm{fF}$ \\
$-\mathrm{R}_{\mathrm{z}}, \mathrm{C}_{\mathrm{z}}$ & \\
$-\mathrm{R}_{\mathrm{x}}, \mathrm{C}_{\mathrm{x}}$ & $2.12 \mathrm{~mW}$ \\
\hline Power consumption $@ \mathrm{I}_{\mathrm{b} 1}=50 \mu \mathrm{A}$, & \\
$\mathrm{I}_{\mathrm{b} 2}=\mathrm{I}_{\mathrm{b} 3}=100 \mu \mathrm{A}$ & \\
\hline
\end{tabular}

Tab. 2. Simulated specifications of MCCFTA.

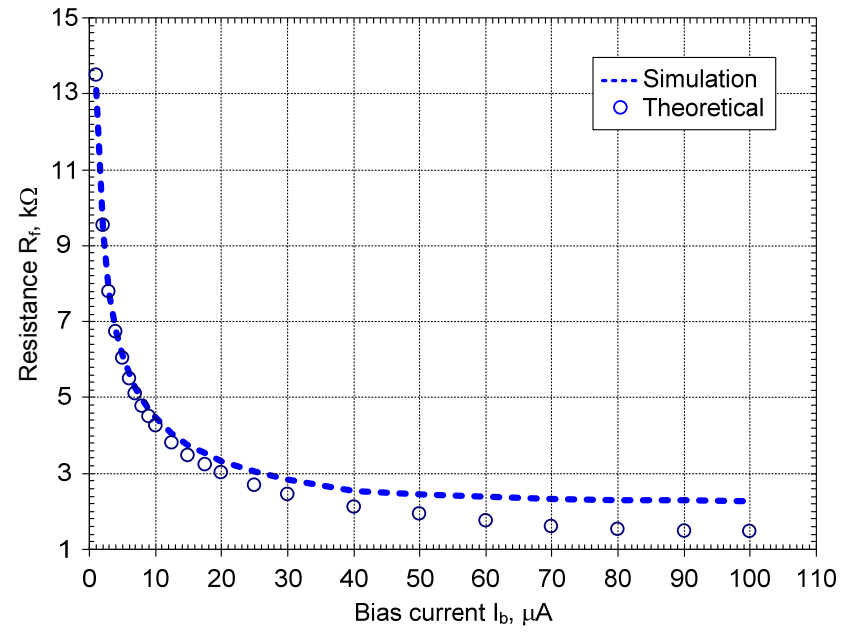

Fig. 5. Simulated resistance $R_{\mathrm{f}}$ when bias current is varied.

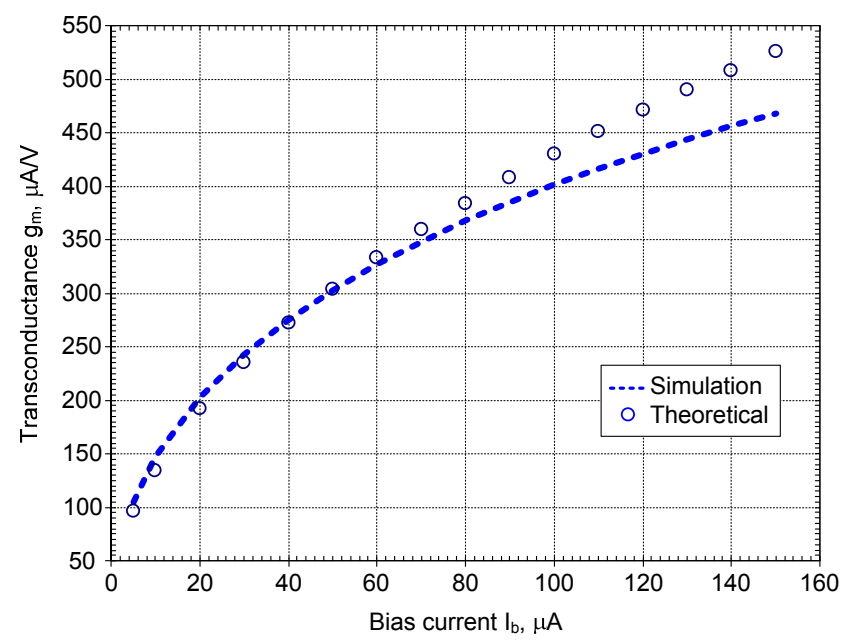

Fig. 6. Simulated transconductance $g_{m}$ when bias current is varied.

$66 \mu \mathrm{A}_{\mathrm{P}-\mathrm{P}}$, respectively. THD will be increased if output signal level was increased which can be obtained by increased CO. However, increasing CO may be increased nonlinear behavior of the system which is results in high THD output signal that should be avoided.

The electronic tuning of the oscillator was shown in Fig. 9. The result gives a variation of the FO from 1.1 to $3.25 \mathrm{MHz}$ with $I_{\mathrm{b} 1}$ in the range of 1 to $50 \mu \mathrm{A}$ that was confirmed by (15). This FO was achieved without adjusting the $\mathrm{CO}$. It shows that the simulated FO was consistent with the theoretical values. At $I_{\mathrm{b} 1}=50 \mu \mathrm{A}$, the error of FO between the simulated and theoretical values was $4.9 \%$. The bias current $I_{\mathrm{b} 1}$ can be continuously varied high up to $100 \mu \mathrm{A}$, but the $g_{m 2}$ must be adjusted via $I_{\mathrm{b} 3}$ to satisfy the CO. However, it was also found that there was a deviation between the theoretical and simulated values in large bias current value region over the value of $50 \mu \mathrm{A}$. From Fig. 9, output signal levels of $V_{1}, V_{2}, I_{1}, I_{2}, I_{3}$, and $I_{4}$ versus $f_{\mathrm{o}}$ have been obtained as shown in Fig. 10. It should be noted that the output signal level is not equal and constant when $I_{\mathrm{b} 1}$ was varied. This problem can be solved by using automatic gain control (AGC) circuit. There are oscillators with AGC available in literature [58-61]. These techniques use AGC 
circuit including into the loop of the system for controlling the amplitude of signal. Usually, AGC is suitable for applying to linear control of $\mathrm{CO}$ and $\mathrm{FO}$ oscillator, if nonlinear control of $\mathrm{CO}$ and $\mathrm{FO}$ such as this work (adjusting $\mathrm{CO}$ and FO in square-root domain), current squaring circuits [62], [63] are required to compensate the square-root form to obtain linear current control of $\mathrm{CO}$ and FO.

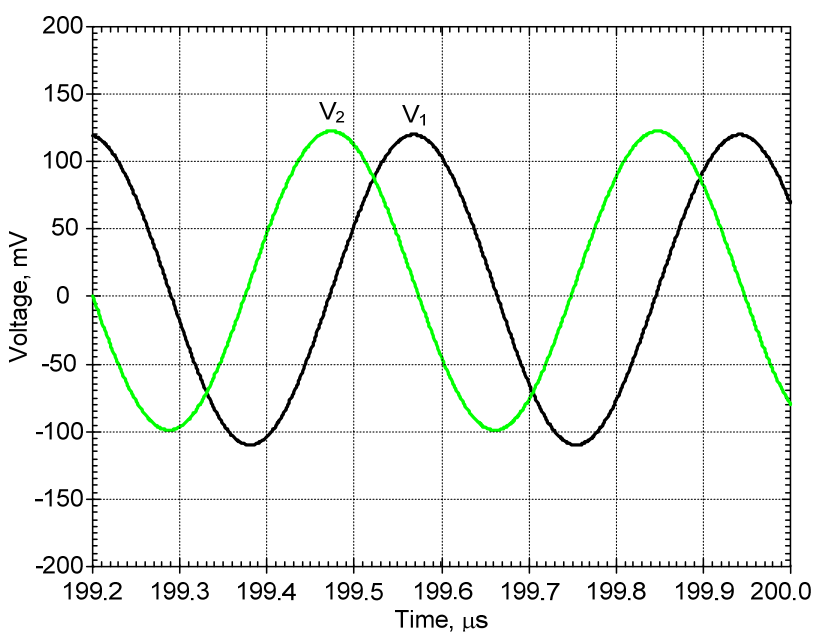

Fig. 7. Simulated two voltage output waveforms.

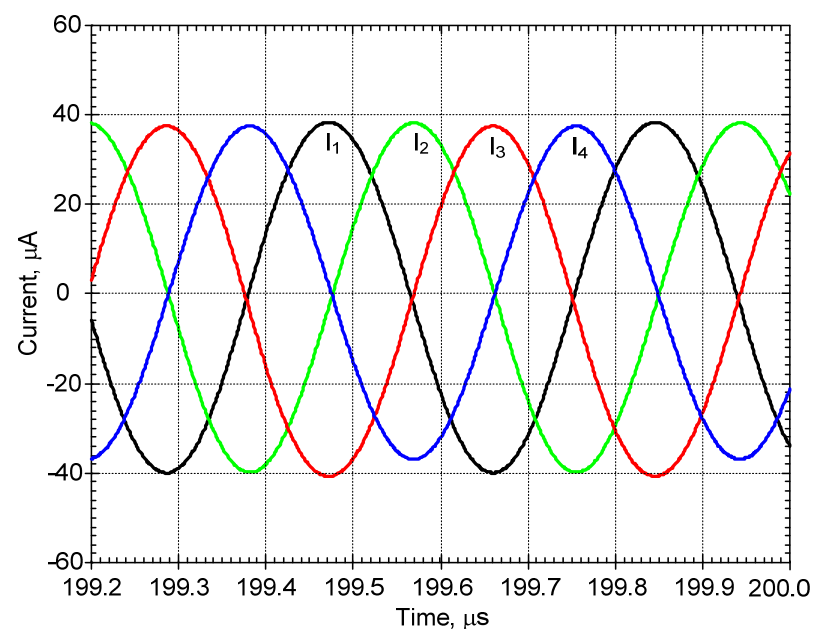

Fig. 8. Simulated four current output waveforms.

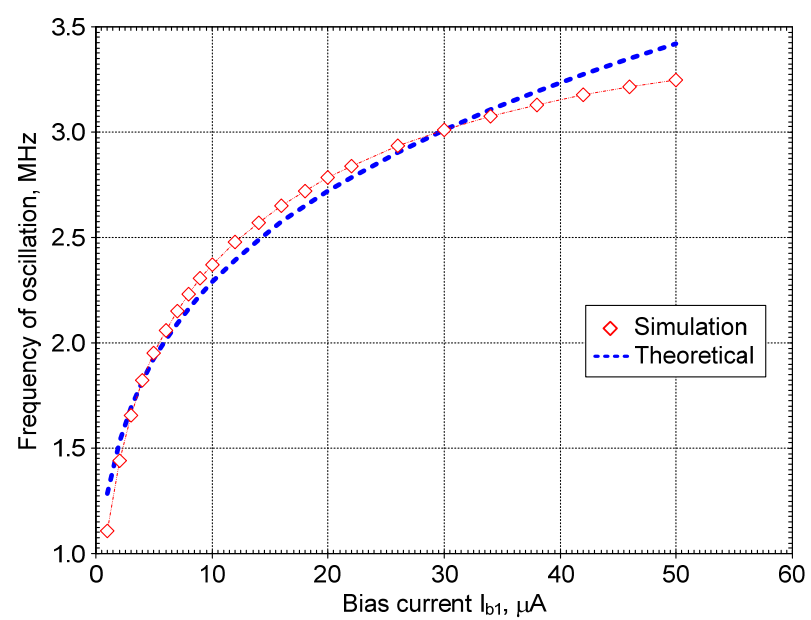

Fig. 9. Electronic frequency tuning with the bias current $I_{\mathrm{b} 1}$.

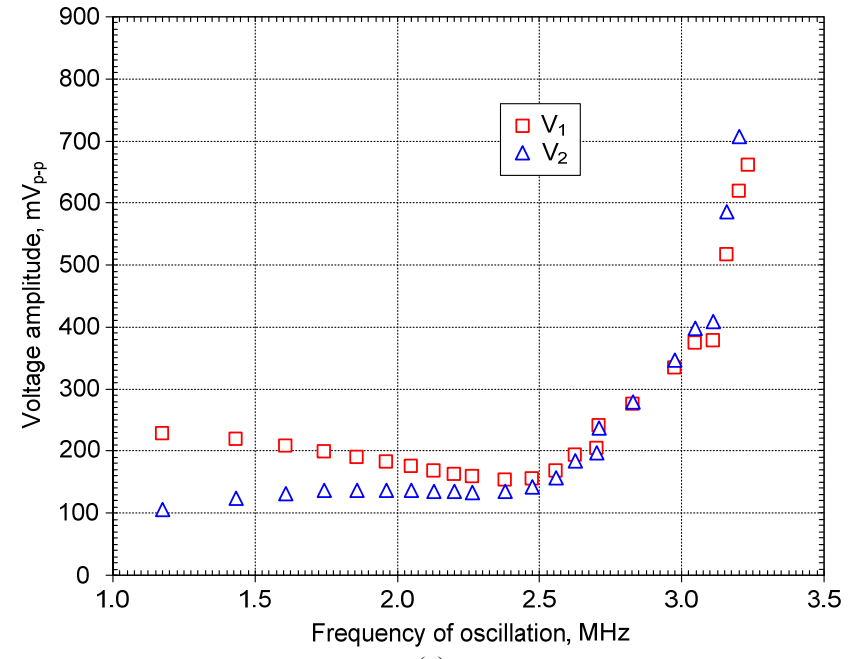

(a)

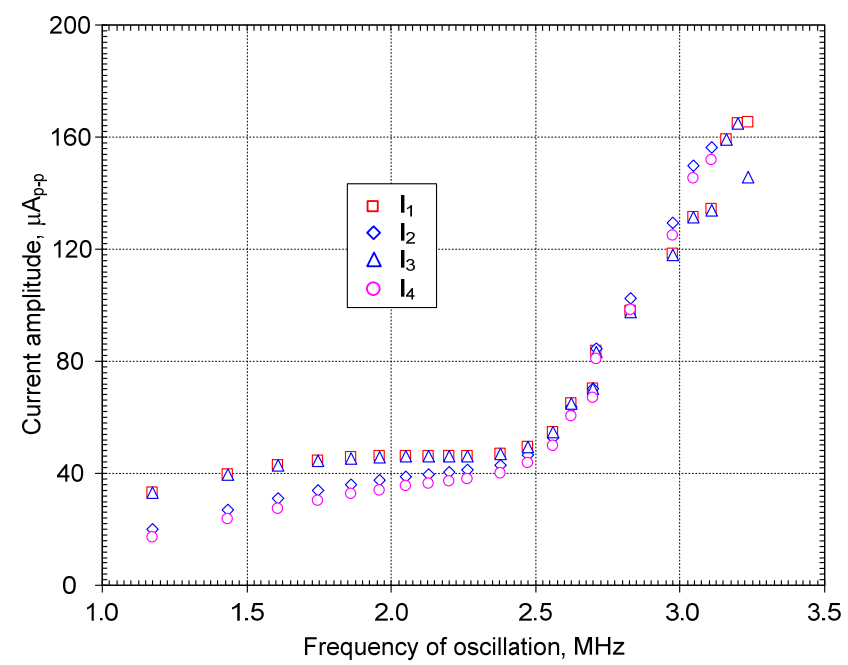

(b)

Fig. 10. Output level versus $f_{0}$ : (a) $V_{1}$ and $V_{2}$, (b) $I_{1}, I_{2}, I_{3}$ and $I_{4}$.

Total harmonic distortion (THD) and phase error were shown in Figs 11 and 12, respectively. From Fig. 11, THD was increased when $I_{\mathrm{b} 1}\left(R_{f}\right)$ was varied far from satisfying condition.

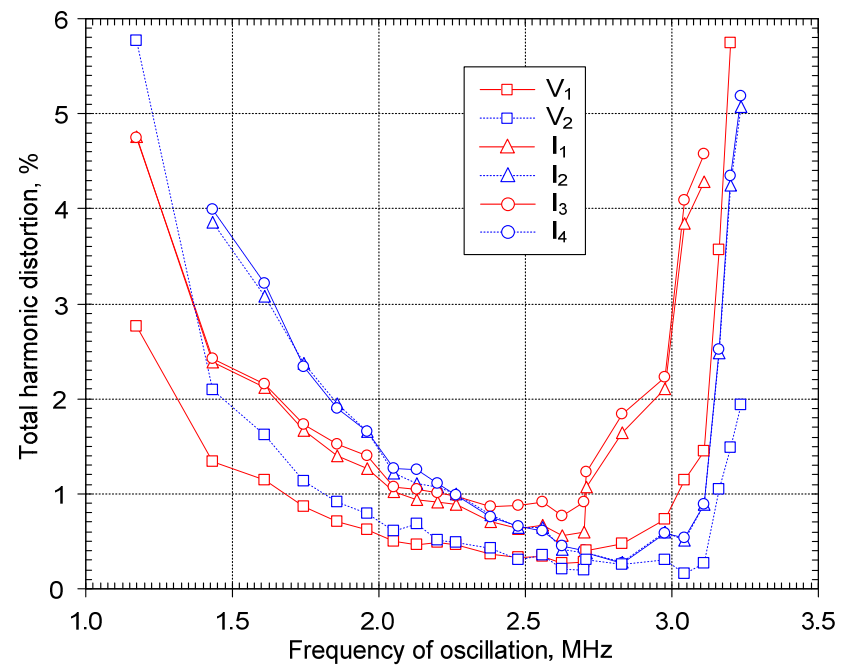

Fig. 11. Simulated THD versus $f_{0}$. 


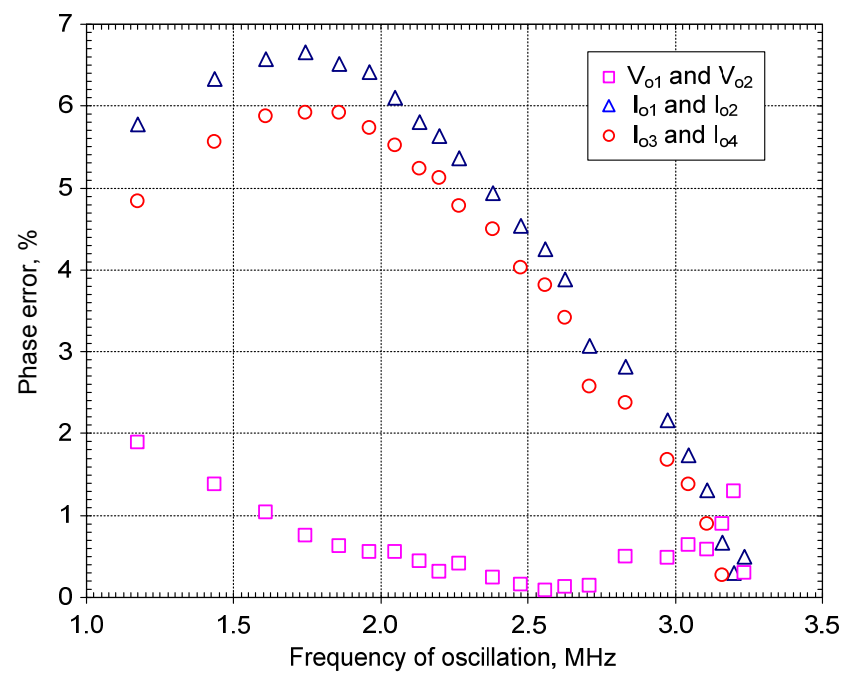

Fig. 12. Simulated phase error versus $f_{\text {o. }}$.

\section{Experimental Results}

The proposed oscillator was experimentally tested wherein the functionality of the MCCFTA was implemented using CFOA AD844 and OTA LM13600 as shown in Fig. 13. The supply voltage $\pm 10 \mathrm{~V}$ was used. The noninstrument of oscilloscope as measurable currents is available to the authors. However, for sake of experimental results, the current outputs, $I_{1}, I_{2}, I_{3}$ and $I_{4}$, can be obtained by connecting the external resistors. In this experiment, current outputs $I_{1}, I_{2}, I_{3}$ and $I_{4}$ were connected to the resistors $50 \mathrm{k} \Omega$ and voltage across these resistors will be measured. To obtain the experimental results, Tektronix MSO

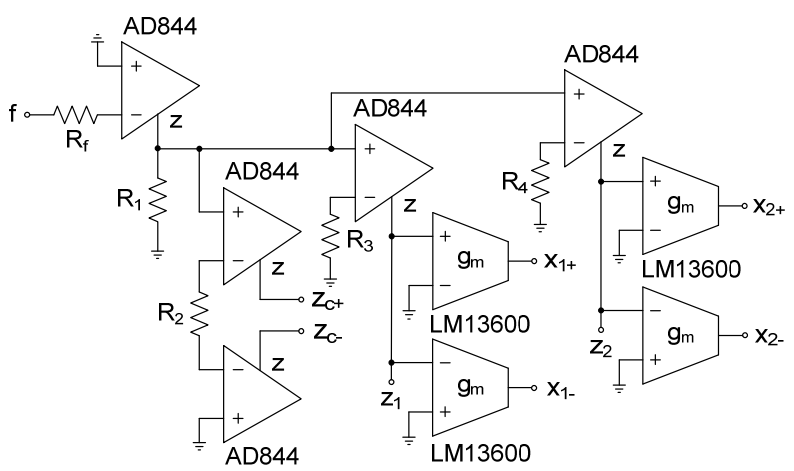

Fig. 13. Possible realization of the MCCFTA using commercial active devices (AD844 and LM13600).

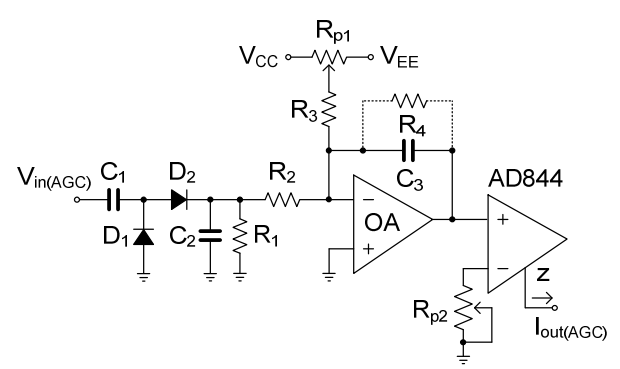

Fig. 14. Amplitude-automatic gain control circuit [61].
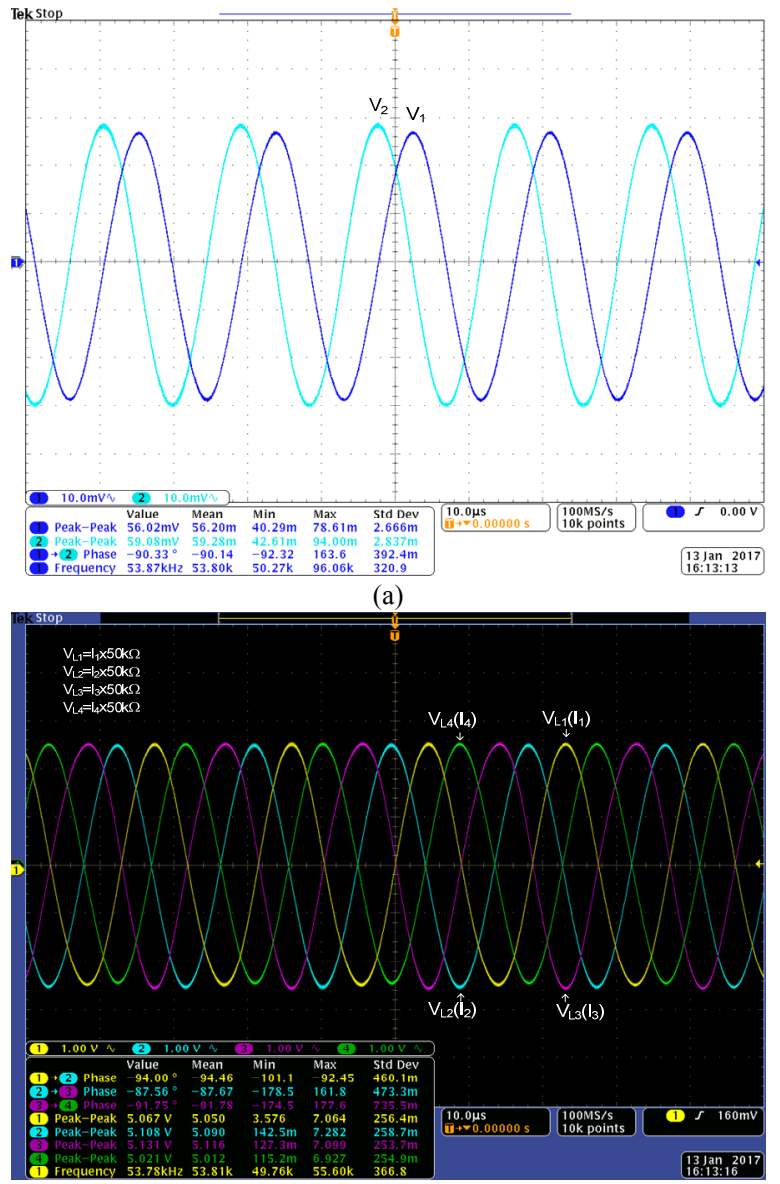

(b)

Fig. 15. Measured waveforms for: (a) voltage outputs, (b) current outputs.

4034 oscilloscope and Keysight N9030A spectrum analyzer were used. The capacitors were designed with $C_{1}=$ $C_{2}=C_{3}=5 \mathrm{nF}$. The resistors $R_{1}, R_{2}, R_{3}$ and $R_{4}$ in Fig. 13 were given as $1 \mathrm{k} \Omega$. The variable resistor was used to obtain the effect of variable $g_{m}$ and $R_{f}$.

To control the output amplitude of signals to be constant, the amplitude-automatic gain control (AGC) circuit in Fig. 14 was used. This circuit was adopted from [61]. From our pretest on the proposed circuit, it was found that $V_{1}\left(I_{1}\right.$ and $\left.I_{3}\right)$ was dependent on tuning of FO, thus $V_{1}$ will be used for the input of AGC circuit $\left(\mathrm{V}_{\mathrm{in}(\mathrm{AGC})}\right)$. CFOA AD844 and $R_{p 2}$ were used to work as voltage-to-current converter (V-I converter). The current output $I_{\text {out(AGC) }}$ of AGC circuit will be supplied additionally to bias current $I_{\mathrm{b} 3}$ for compensating $\mathrm{CO}$. The active device and passive-value used in Fig. 14 were tabulated in Tab. 3.

The quadrature sinusoidal voltage and current output waveforms with resistor $R_{f}=500 \Omega$, bias currents $I_{\mathrm{b} 2}=$ $50 \mu \mathrm{A}\left(g_{\mathrm{m} 2}=1 \mathrm{~mA} / \mathrm{V}\right)$ and $I_{\mathrm{b} 3}=61.8 \mu \mathrm{A}$ were shown in Fig. 15, (a) and (b), respectively. It should be noted that the quadrature sinusoidal signal was almost equal of amplitude. The FO was found as $53 \mathrm{kHz}$. From Fig. 15, the THDs for $V_{1}, V_{2}, I_{1}, I_{2}, I_{3}$ and $I_{4}$ were about $1.2,0.9,1.2,1.1,1.3$ and $1.1 \%$, respectively. The quadrature relationship was further verified through the X-Y plots of the two output forms in Fig. 15 as shown in Fig. 16, (a) and (b), respectively. 


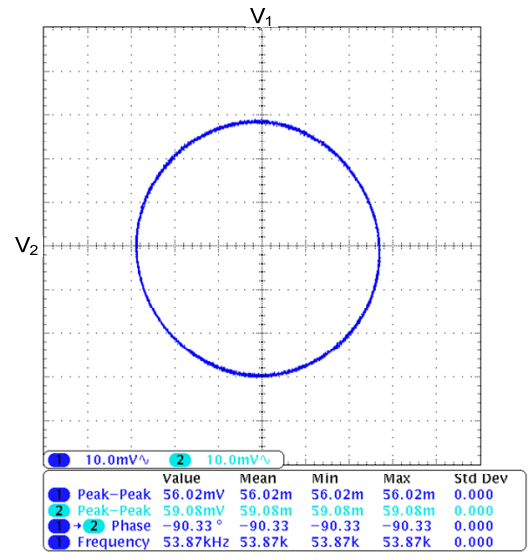

(a)

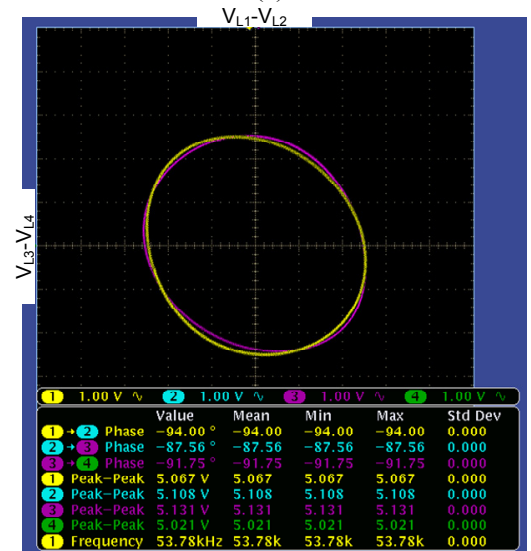

(b)

Fig. 16. X-Y plots for: (a) voltage output, (b) current output.

\begin{tabular}{|l|c|}
\hline \multicolumn{1}{|c|}{ Device } & Value \\
\hline $\mathrm{OA}$ & OPA2650 \\
\hline $\mathrm{D}_{1}, \mathrm{D}_{2}$ & $2 \times \mathrm{xAT} 42$ \\
\hline $\mathrm{C}_{1}, \mathrm{C}_{2}$ & $1 \mu \mathrm{F}$ \\
\hline $\mathrm{C}_{3}$ & $10 \mathrm{nF}$ \\
\hline $\mathrm{R}_{1}, \mathrm{R}_{4}$ & $1 \mathrm{M} \Omega$ \\
\hline $\mathrm{R}_{2}, \mathrm{R}_{3}$ & $100 \mathrm{k} \Omega$ \\
\hline $\mathrm{R}_{5}$ & $200 \Omega$ \\
\hline $\mathrm{R}_{\mathrm{p} 1}$ and $\mathrm{R}_{\mathrm{p} 2}$ & $100 \mathrm{k} \Omega$ (variable resistor) \\
\hline
\end{tabular}

Tab. 3. Active and passive components used in Fig. 14.

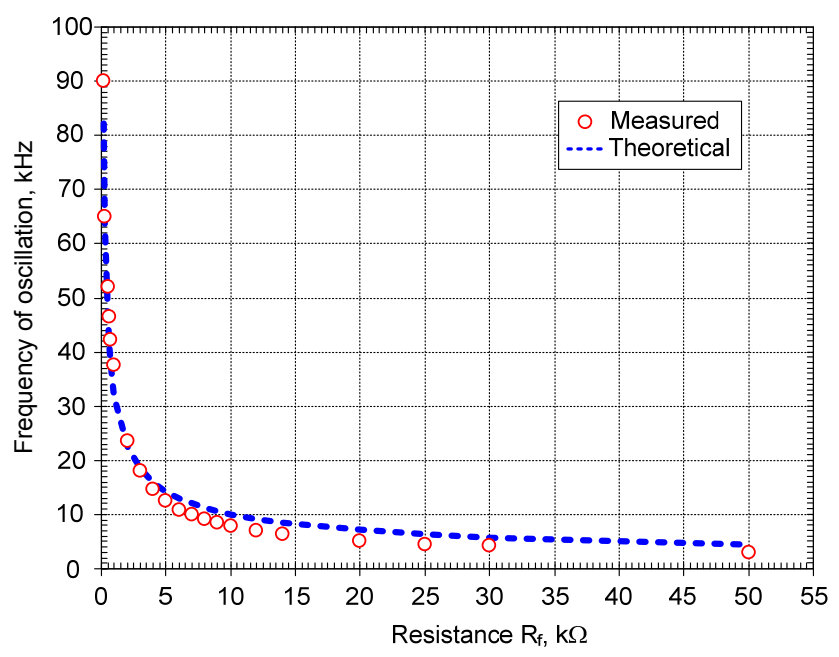

Fig. 17. FO tuning with $R_{f}$.

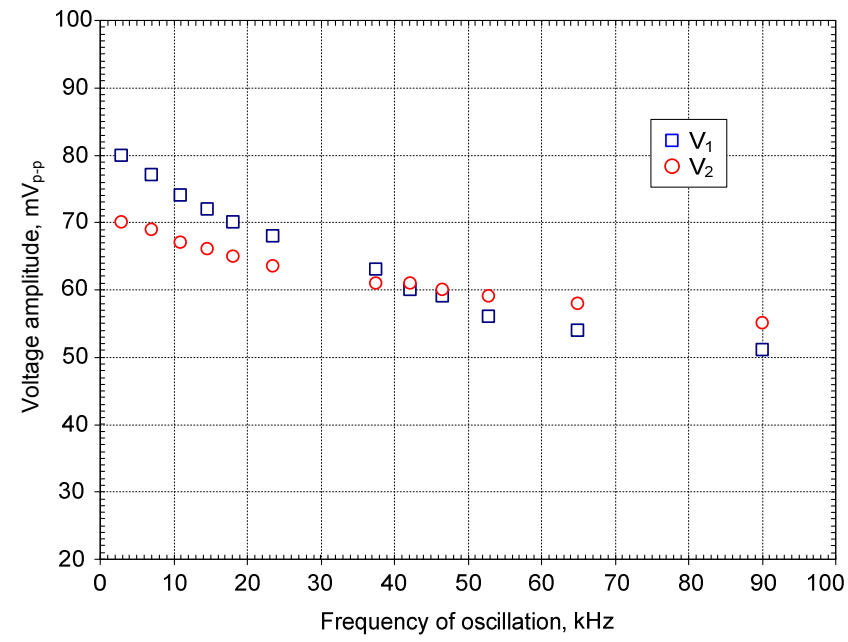

Fig. 18. Output level of $V_{1}$ and $V_{2}$ versus $f_{0}$.

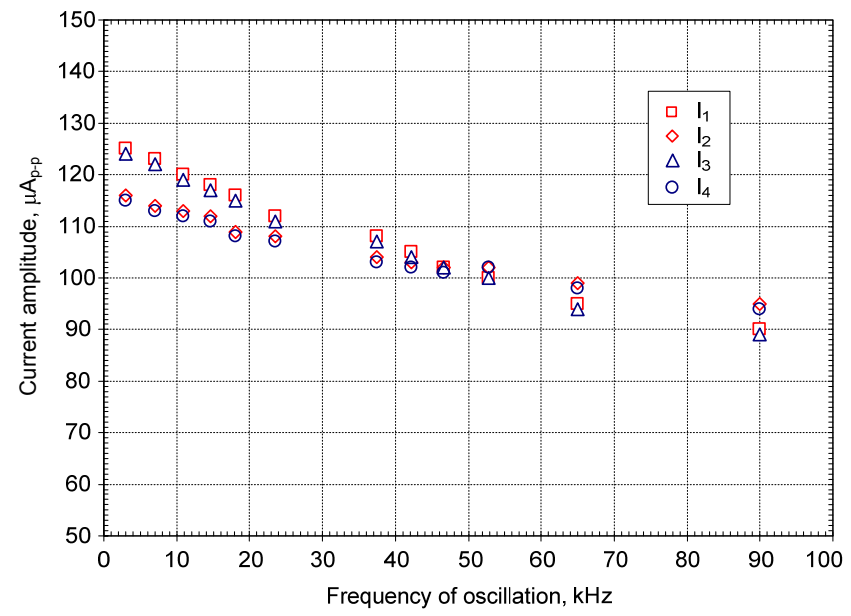

Fig. 19. Output level of $I_{1}, I_{2}, I_{3}$ and $I_{4}$ versus $f_{\mathrm{o}}$.

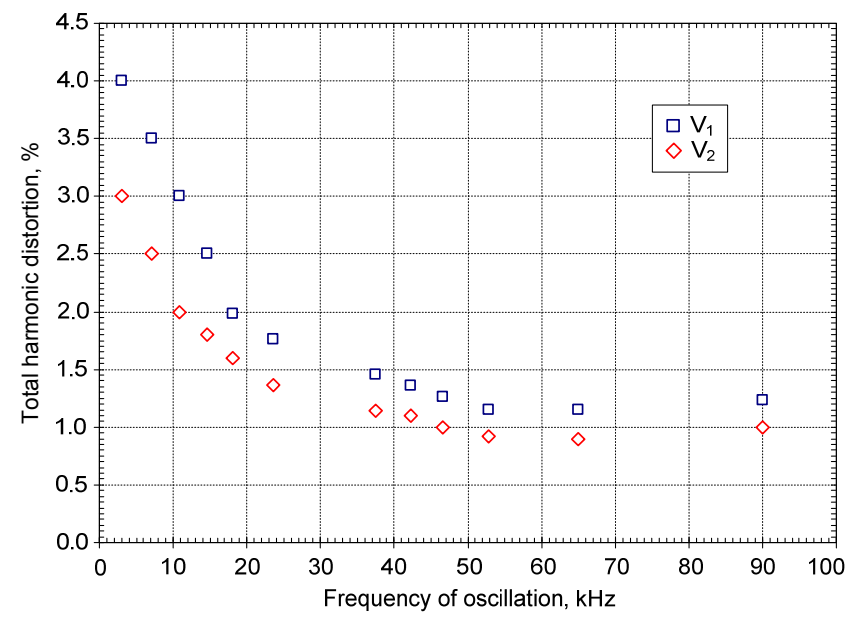

Fig. 20. Measured THD of voltage outputs versus $f_{\mathrm{o}}$.

Figure 17 shows the experimental results of the FO by changing the value of the resistor $R_{f}$ with $C_{1}=C_{2}=C_{3}=$ $5 \mathrm{nF}, I_{\mathrm{b} 1}=50 \mu \mathrm{A}$ and $I_{\mathrm{b} 3}=61.8 \mu \mathrm{A}$. The tuning of the oscillator gives a variation of the FO from 2.9 to $90 \mathrm{kHz}$ when $R_{f}$-value was decreased from 50 to $0.15 \mathrm{k} \Omega$. In this case, FO was obtained by adjusting CO via AGC. The plots for theoretical value were also included for comparison. 


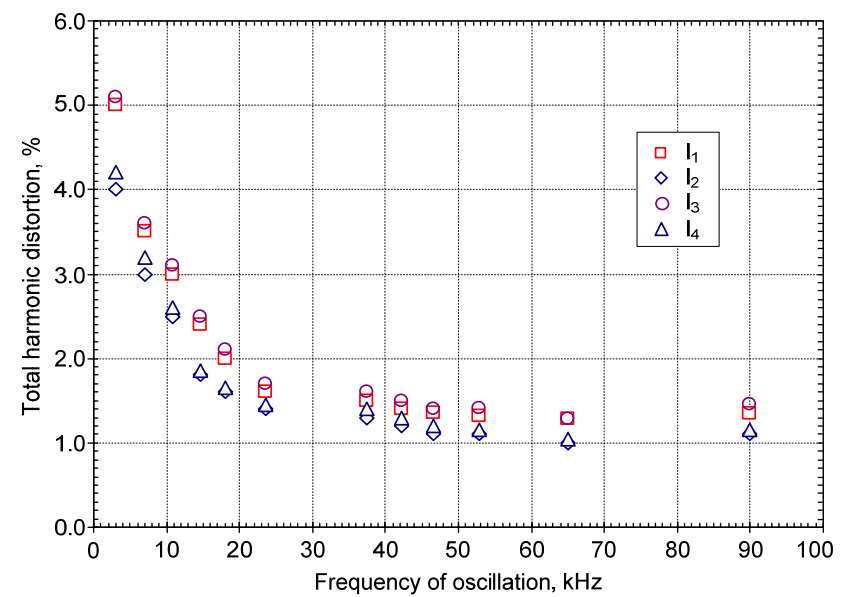

Fig. 21. Measured THD of current outputs versus $f_{0}$.

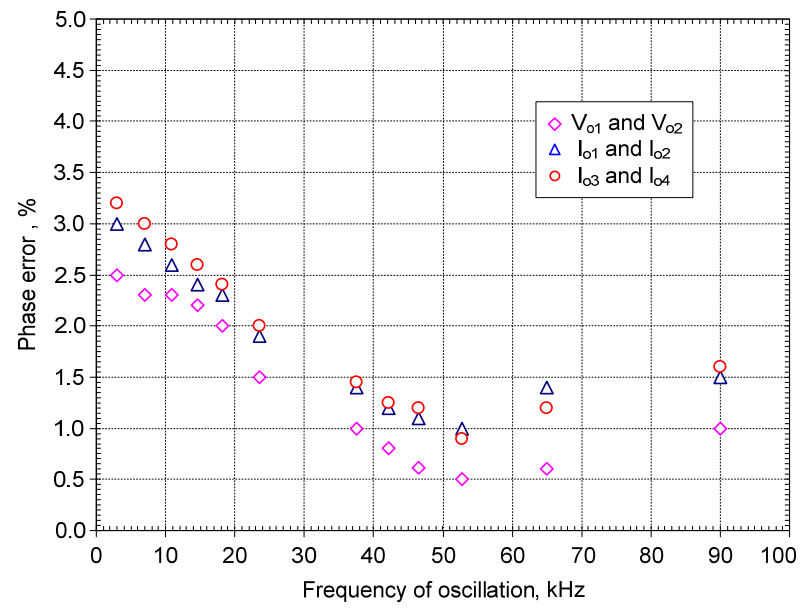

Fig. 22. Measured phase error versus $f_{\text {o. }}$.

From Fig. 17, output signal level of $V_{1}$ and $V_{2}$ versus $f_{\mathrm{o}}$ and output signal level of $I_{1}, I_{2}, I_{3}$ and $I_{4}$ versus $f_{\mathrm{o}}$ were shown in Fig. 18 and 19, respectively. It should be noted that the amplitude was not fluctuated; thanks to AGC for obtaining this result. THDs for voltage outputs and current outputs versus $f_{\mathrm{o}}$ were measured and shown in Figs. 20 and 21 . Finally, phase errors versus $f_{\mathrm{o}}$ were also measured and shown in Fig. 22.

Compared between the simulation and experimental results, setting of FO-value and working capacitor-value were different. Actually, this work focuses on the QO which should be implemented as IC form. Unfortunately, the obstruction for fabricating was the cost. Although, higher FO for experimental results was possible, but our test was investigated the circuit which builds on perfboard. Using printed circuit board and high quality active devices the operation band of the circuit [59-61] will be increased. Therefore, this experimental result was used only to confirm the workability of the proposed structure.

\section{Conclusions}

In this paper, a mixed-mode third-order QO based on new MCCFTA has been presented. The proposed circuit uses only one MCCFTA and three grounded capacitors. The use of grounded capacitors is ideally interesting from an integration point of view. The proposed structure provides four high output impedance current sources with $90^{\circ}$ phase difference, thus these output terminals can be directly connected to the loads without additional follower circuits. In addition, voltage with $90^{\circ}$ phase difference can be obtained without changing any topology. Also the $\mathrm{CO}$ and FO can be controlled orthogonally and electronically by adjusting the bias currents of MCCFTA. The active and passive sensitivities are no more than unity of magnitude. Simulation and experimental results, which confirm the theoretical analysis, are included.

\section{Acknowledgments}

The authors would like to express sincere appreciation to the anonymous reviewers and editor for their valuable comments. The research described in this paper was financed by the Czech Ministry of Education in frame of the National Sustainability Program under grant LO1401 and by the Czech Science Foundation under grant No. P102-15-21942S. For research, infrastructure of the SIX Center was used.

\section{References}

[1] TOUMAZOU, C., LidGEy, F., MAKRIS, C. A. Extending voltage-mode op amps to current-mode performance, IEE Proceeding Part-G, 1990, vol. 137, p. 116-130. DOI: 10.1049/ipg-2.1990.0020

[2] BIOLEK, D. CDTA-building block for current-mode analog signal processing, In Proceedings of European Conference on Circuit Theory and Design (ECCTD). Poland, 2003, p. 397-400, vol. III.

[3] HAYKIN, S., MOHER, M. An Introduction to Analog and Digital Communications. New York: John Wiley \& Sons, 2007. ISBN-13: 978-0471432227

[4] BOLTON, W. Measurement and Instrumentation Systems. Oxford: Newnes, 1996. ISBN-9780128011324

[5] KESKIN, A. U., BIOLEK, D. Current mode quadrature oscillator using current differencing transconductance amplifiers (CDTA). IEE Proceeding of Circuits Devices and Systems, 2006, vol. 153, p. 214-218: DOI: $10.1049 /$ ip-cds: 20050304

[6] LAHIRI, A. Novel voltage/current-mode quadrature oscillator using current differencing transconductance amplifier. Analog Integrated Circuits and Signal Processing, 2009, vol. 61, p. 199 to 203. DOI: $10.1007 / \mathrm{s} 10470-009-9291-0$

[7] BIOLEK, D., KESKIN, A. U., BIOLKOVA, V. Grounded capacitor current mode single resistance-controlled oscillator using single modified current differencing transconductance amplifier. IET Circuits, Devices and Systems, 2009, vol. 4, p. 496-520. DOI: 10.1049/iet-cds.2009.0330

[8] BUMRONGCHOKE, T., DUANGMALAI, D., JAIKLA, W Current differencing transconductance amplifier based currentmode quadrature oscillator using grounded capacitors. In Proceedings of 2010 International Communications and Information Technologies (ISCIT). Japan, 2010, p. 192-195. DOI: 10.1109/ISCIT.2010.5664834

[9] JAIKLA, W., SIRIPRUCHYANUN, M., BAJER, J., BIOLEK, D. 
A simple current-mode quadrature oscillator using single CDTA. Radioengineering, 2008, vol. 17, no. 4, p. 33-40.

[10] KUMNGERN, M., LAMUN, P., DEJHAN, K. Current-mode quadrature oscillator using current differencing transconductance amplifiers. International Journal of Electronics, 2012, vol. 99, p. 971-986. DOI: 10.1080/00207217.2011.651693

[11] JAIKLA, W., LAHIRI, A. Resistor-less current-mode four-phase quadrature oscillator using CCCDTAs and grounded capacitors. International Journal of Electronics and Communications, 2012, vol. 66, p. 214-218. DOI: 10.1016/j.aeue.2011.07.001

[12] JIN, J., WANG, C. Single CDTA-based current-mode quadrature oscillator. International Journal of Electronics and Communications, 2012, vol. 66, p. 933-936. DOI: 10.1016/j.aeue.2012.03.018

[13] BIOLEK, D., SENANI, R., BIOLKOVA, V., KOLKA, Z. Active elements for analog signal processing: classification: Review and new proposals. Radioengineering, 2008, vol. 17, no. 4, p. 15-32.

[14] HERENCSAR, N. KOTON, J. VRBA, K., LAHIRI, A. Floating simulators based on current follower transconductance amplifiers (CFTAs). In Proceedings of the European Conference of Circuits Technology and Devices. Tenerife (Spain), 2010, p. 23-26.

[15] HERENCSAR, N., KOTON, J., VRBA, K., CICEKOGLU, O. New active-C grounded positive inductance simulator based on CFTAs. In Proceedings of 33rd International Conference on Telecommunications and Signal Processing. Czech Republic, 2010, p. 35-37.

[16] HERENCSAR, N., KOTON, J., VRBA, K. Realization of currentmode KHN-equivalent biquad using current follower transconductance amplifiers (CFTAs). IEICE Transactions on Fundamentals of Electronics, Communications and Computer Sciences, 2010, vol. E93.A, p. 1816-1819. DOI: 10.1587/transfun.E93.A.1816

[17] HERENCSAR, N., KOTON, J., VRBA, K., LATTENBERG, I. Current follower transconductance amplifier (CFTA)-a useful building block for analog signal processing. Journal of Active and Passive Electronic Devices, 2011, vol. 6, p. 217-229.

[18] INTAWICHAI, K., TANGSRIRAT, W. Signal flow graph realization of nth-order current-mode allpass filters using CFTAs. In Proceedings of 2013 10th International Conference on Electrical Engineering/Electronics, Computer, Telecommunications and Information Technology (ECTI-CON). Thailand, 2013, p. 1-6. DOI: 10.1109/ECTICon.2013.6559519

[19] TORTEANCHAI, U., KUMNGERN, M. First-order allpass network using CFTA. In Proceedings of 2014 th Joint International Conference on Information and Communication Technology, Electronic and Electrical Engineering (JICTEE). Thailand, 2014, p. 1-4. DOI: 10.1109/JICTEE.2014.6804120

[20] HERENCSAR, N., VRBA, K., KOTON, J., LAHIRI, A. Realisations of single-resistance-controlled quadrature oscillators using a generalised current follower transconductance amplifier and a unity-gain voltage-follower. International Journal of Electronics, 2010, vol. 97, p. 897-906. DOI: $10.1080 / 00207211003733320$

[21] TANGSRIRAT, W., MONGKOLWAI, P., PUKKALANUN, T. Current-mode high-Q bandpass filter and mixed-mode quadrature oscillator using ZC-CFTAs and grounded capacitors. Indian Journal of Pure \& Applied Physics, 2012, vol. 50, p. 600-607. URI: http://hdl.handle.net/123456789/14480

[22] PRASERTSOM, D., TANGSRIRAT, W. Current gain controlled CFTA and its application to resistorless quadrature oscillator. In Proceedings of 2012 9th International Conference on Electrical Engineering/Electronics, Computer, Telecommunications and Information Technology (ECTI-CON). Thailand, 2012, p. 1-4. DOI: 10.1109/ECTICon.2012.6254271

[23] LAMUN, P. KUMNGERN, M., TORTEANCHAI, U.,
SARSITTHITHUM, K. Tunable current-mode quadrature sinusoidal oscillator using CCCFTAs and grounded capacitors. In Proceedings of 2013 4th International Conference on Intelligent Systems, Modelling and Simulation (ISMS). Thailand, 2013, p. 665-668. DOI: 10.1109/ISMS.2013.138

[24] KUMNGERN, M., LAMUN, P., JUNNAPIYA, S. CFTA-based electroniccally tunable quadrature sinusoidal oscillator. In Proceedings of 2014 International Electrical Engineering Congress (iEECON). Thailand, 2014, p. 1-4. DOI: 10.1109/iEECON.2014.6925891

[25] PHATSORNSIRI, P., LAMUN, P. Tunable current-mode quadrature oscillator using CFTAs and grounded capacitors. In Proceedings of 2015 12th International Conference on Electrical Engineering/Electronics, Computer, Telecommunications and Information Technology (ECTI-CON). Thailand, 2015, p. 1-4. DOI: 10.1109/ECTICon.2015.7207104

[26] SRISAKULTIEW, S., SIRIPRUCHYANUN, M., JAIKLA, W. Single-resistance-controlled current-mode quadrature sinusoidal oscillator using single CCCFTA with grounded elements. In Proceedings of 2013 36th International Conference on Telecommunications and Signal Processing (TSP). Rome (Italy), 2013, p. 436-439. DOI: 10.1109/TSP.2013.6613969

[27] VAN VALKENBURG, M. E. Analog Filter Design. Holt Sounders International Edition, 1987.

[28] RUBIOLA, E. Phase Noise and Frequency Stability in Oscillators. Cambridge University Press, 2010. ISBN-13: 9780521153287

[29] RAZAVI, B. A study of phase noise in CMOS oscillators. IEEE Journal of Solid-State Circuits, 1996, vol. 31, p. 331-343. DOI: 10.1109/9780470545492.ch19

[30] PROMMEE, P. DEJHAN, K. An integrable electronic-controlled quadrature sinusoidal oscillator using $\mathrm{CMOS}$ operational transconductance amplifier. International Journal of Electronics, 2002, vol. 89, p. 365-379. DOI: 10.1080/713810385

[31] HORNG, J.-W. Quadrature oscillators using operational amplifiers. Active and Passive Electronic Components, vol. 2011, Article ID 320367. DOI: 10.1155/2011/320367

[32] HORNG, J.-W., HOU, C.-L., CHANG, C.-M., CHUNG, W.-Y., TANG, H.-I., WEN, Y.-I. Quadrature oscillator using CCIIs. International Journal of Electronics, 2005, vol. 92, p. 21-31. DOI: $10.1080 / 00207210412331332899$

[33] HORNG, J.-W. Current/voltage-mode third order quadrature oscillator employing two multiple outputs CCIIs and grounded capacitors. Indian Journal of Pure \& Applied Physics, 2011, vol. 49, p. 494-498. URI: http://hdl.handle.net/123456789/12012

[34] KOTON, J., HERENCSAR, N., VRBA, K., METIN, B. Currentand voltage-mode third-order quadrature oscillator. In Proceedings of 2012 13th International Conference on Optimization of Electrical and Electronic Equipment (OPTIM). Romania, 2012, p. 1203-1206. DOI: 10.1109/OPTIM.2012.6231795

[35] CHATURVEDI, B., MAHESHWARI, S. Third-order quadrature oscillator circuit with current and voltage outputs. ISRN Electronics, vol. 2013, Article ID 385062, DOI: $10.1155 / 2013 / 385062$

[36] PANDEY, R., PANDEY, N., KOMANAPALLI, G., ANURAG, R. OTRA based voltage mode third order quadrature oscillator. ISRN Electronics, vol. 2014, Article ID: 126471, p. 1-5. DOI: $10.1155 / 2014 / 126471$

[37] KUMNGERN, M., KANSIRI, I. Single-element control thirdorder quadrature oscillator using OTRAs. In Proceedings 2014 12th ICT and Knowledge Engineering (ICT\&KE). Thailand, 2014, p. 24-27. DOI: 10.1109/ICTKE.2014.7001529

[38] MAHESHWARI, S., KHAN, I. A. Current controlled third order quadrature oscillator. IEE Proceeding of Circuits Devices and System, 2005, vol. 152, p. 605-607. DOI: 10.1049/ipcds. 20045185 
[39] MAHESHWARI, S. Current-mode third-order quadrature oscillator. IET Circuits, Devices and Systems, 2010, vol. 4, p. 188 to 195. DOI: 10.1049/iet-cds.2009.0259

[40] HORNG, J.-W. Current-mode third-order quadrature oscillator using CDTAs. Active and Passive Electronic Components, vol. 2009, Article ID 789171. DOI: 10.1155/2009/789171

[41] HORNG, J.-W., LEE, H., WU, J.-Y. Electronically tunable thirdorder quadrature ocillator using CDTAs. Radioengineering, 2010, vol. 19 , p. 326-330.

[42] KUMNGERN, M., JUNNAPIYA, S. Current-mode third-order quadrature oscillator using minimum elements. In Proceedings of International Conference on Electrical Engineering and Informatics (ICEEI). Indonesia, 2011, p. 1-4. DOI: 10.1109/ICEEI.2011.6021799

[43] LAWANWISUT, S., SIRIPRUCHAYANUN, M. High outputimpedance current-mode third-order quadrature oscillator based on CCCCTAs. In Proceedings of 2009 IEEE Region 10 Conference $(T E N C O N)$. Singapore, 2009, p. 1-4. DOI: 10.1109/TENCON.2009.5395961

[44] DUANGMALAI, D., JAIKLA, W. Realization of current-mode quadrature oscillator based on third order technique. ACEEE International Journal on Electrical and Power Engineering, 2011, vol. 2, p. 46-49. Available at: http://agritech.pcru.ac.th/new/doc/3rd\%20oscillator-20120222093615.pdf

[45] PANDEY, R., PANDEY, N., PAUL, S. K. MOS-C third order quadrature oscillator using OTRA. In Proceedings of 2012 Third International Conference on Computer and Communication Technology (ICCCT). India, 2012, p. 77-80. DOI: 10.1109/ICCCT.2012.24

[46] PHANRUTTANACHAI, K., JAIKLA, W. Third order currentmode quadrature sinusoidal oscillator with high output impedances. World Academy of Science, Engineering and Technology, 2013, vol. 7, p. 472-475.

[47] PANDEY, N., PANDEY, R. Approach for third order quadrature oscillator realization. IET Circuits, Devices \& Systems, 2015, vol. 9, p. 161-171. DOI: 10.1049/iet-cds.2014.0170

[48] PROMMEE, P., ANGKEAW, K. Log-domain current-mode thirdorder sinusoidal oscillator. In Proceedings of 2011 IEEE 54th International Midwest Symposium on Circuits and Systems (MWSCAS). Korea, 2011, p. 1-4

[49] KUMNGERN, M., CHANWUTITUM, J. Single MCCCCTAbased mixed-mode third-order quadrature oscillator. In Proceedings of Fourth International Conference on Communications and Electronics (ICCE). Vietnam, 2012, p. 426 to 429. DOI: 10.1109/CCE.2012.6315943

[50] PANDEY, R., PANDEY, N., KOMANAPALLI, G., ANURAG, R. OTRA based voltage mode third order quadrature oscillator. ISRN Electronics, vol. 2014, Article ID 126471.

[51] PHATSORNSIRI, P. LAMUN, P. KUMNGERN, M. TORTEANCHAI, U. Current-mode third-order quadrature oscillator using VDTAs and grounded capacitors. in Proceeding of The 4th Joint International Conference on Information and Communication Technology, Electronic and Electrical Engineering (JICTEE). Thailand, 2014, p. 1-4. DOI: 10.1109/JICTEE.2014.6804103

[52] CHANNUMSIN, O. JANTAKUN, A. Third-order sinusoidal oscillator using VDTAs and grounded capacitors with amplitude controllability. In Proceeding of The 4th Joint International Conference on Information and Communication Technology, Electronic and Electrical Engineering (JICTEE). Thailand, 2014, p. 1-4. DOI: 10.1109/JICTEE.2014.6804103

[53] HERENCSAR, N., KOTON, J., VRBA, K. LAHIRI, A., CICEKOGLU, O. Current-controlled CFTA-based current-mode SITO universal filter and quadrature oscillator. In Proceedings of
2010 International Conference on Applied Electronics (AE), Czech Republic, 2010, p. 1-4.

[54] LI, Y. A modified CDTA (MCDTA) and its applications: designing current-mode sixth-order elliptic band-pass filter. Circuits, Systems, and Signal Processing, 2011, vol. 30, p. 1383 to 1390. DOI: 10.1007/s00034-011-9329-2

[55] JAIKLA, W., SIRIPRUCHYANUN, M., LAHIRI, A. Resistorless dual-mode quadrature sinusoidal oscillator using a single active building block. Microelectronics Journal, 2011, vol. 42, p. 135 to 104. DOI: $10.1016 /$ j.mejo.2010.08.017

[56] KUMNGERN, M., TORTEANCHAI, U. A current-mode fourphase third-order quadrature oscillator using a MCCCFTA. In Proceedings of 2012 IEEE International Conference on Cyber Technology in Automation, Control, and Intelligent Systems (CYBER). Thailand, 2012, p. 156-159. DOI: 10.1109/CYBER.2012.6392545

[57] BHUSAN, M., NEWCOMB, R. W. Grounding of capacitors in integrated circuits. Electronics Letters, 1967, vol. 3, p. 148-149. DOI: 10.1049/el:19670114

[58] BIOLEK, B., LAHIRI, A., JAIKLA, W., SIRIPRUCHYANUN, M., BIOLKOVA, V. Realization of electronically tunable voltagemode/current-mode quadrature sinusoidal oscillator using ZC-CGCDBA. Microelectronics Journal, 2011, vol. 42, p. 1116-1123. DOI: $10.1016 /$ j.mejo.2011.07.004

[59] SOTNER, R., JERABEK, J., HERENCSAR, N., PETRZELA, J., VRBA, K., KINCL, Z. Linear tunable quadrature oscillator derived from LC Colpitts structure using voltage differencing transconductance amplifier and adjustable current amplifier. Analog Integrated Circuits and Signal Processing, 2014, vol. 81, p. 121-136. DOI: $10.1007 / \mathrm{s} 10470-014-0353-6$

[60] SOTNER, R., HRUBOS, Z., HERENCSAR, N., JERABEK, J., DOSTAL, T., VRBA, K. Precise electronically adjustable oscillator suitable for quadrature signal generation employing active elements with current and voltage gain control. Circuits, Systems, and Signal Processing, 2014, vol. 33, p. 1-35. DOI: $10.1007 / \mathrm{s} 00034-013-9623-2$

[61] SOTNER, R., JERABEK, J., LANGHAMMER, L., POLAK, J. HERENCSAR, N., PROKOP, R., PETRZELA, J., JAIKLA, W. Comparison of two solutions of quadrature oscillators with linear control of frequency of oscillation employing modern commercially available devices. Circuits, Systems, and Signal Processing, 2015, vol. 34, p. 3449-3469. DOI: 10.1007/s00034015-0015-7

[62] BULT, K., WALLINGA, H. A class of analog CMOS circuits based on the square-law characteristic of an MOS transistor in saturation. IEEE Journal of Solid-State Circuits, 1987, vol. 22, p. 357-365. DOI: 10.1109/JSSC.1987.1052733

[63] KUMNGERN, M., DEJHAN, K. Versatile dual-mode class-AB four-quadrant analog multiplier. International Journal of Electrical, Computer, Energetic, Electronic and Communication Engineering, 2008, vol. 2, p. 215-221. Available at: www.waset.org/publications/401

\section{About the Authors ...}

Khachen KHAW-NGAM was born in Surin, Thailand. He received his B.Eng. from Suranaree University of Technology, Nakornratchasima, Thailand, in 1996, and the M.Eng. from King Mongkut's Institute of Technology Ladkrabang (KMITL), Bangkok, Thailand in 2006. He is now pursuing a doctoral degree in Electrical Engineering, KMITL. His research interests include analog signal processing circuit design. 
Montree KUMNGERN received the B.S.Ind.Ed. degree from King Mongkut's University of Technology Thonburi (KMUTT), Bangkok, Thailand, in 1998, the M.Eng. and D.Eng. degrees from King Mongkut's Institute of Technology Ladkrabang (KMITL), Bangkok, Thailand, in 2002 and 2006, respectively, all in major of electrical engineering. He is currently an Assistant Professor at Faculty of Engineering, KMITL. His research interests include analog electronics, analog and digital VLSI circuits and nonlinear electronic circuits. He is author or co-author of more than 150 publications in journals and proceedings of international conferences.

Fabian KHATEB was born in 1976. He received the Ing. and Ph.D. degrees in Electrical Engineering and Communication and also in Business and Management from Brno University of Technology (BUT), Czech Republic in 2002,
2005, 2003 and 2007, respectively. He is currently working as an Associate Professor at the Dept. of Microelectronics BUT and also at the Czech Technical University in Prague, Faculty of Biomedical Engineering, Joint Centre for Biomedical Engineering of the Czech Technical University and Charles University in Prague. He has expertise in new principles of designing low-voltage low-power analog circuits, particularly biomedical applications. He has acted as a reviewer for numerous scientific international journals. $\mathrm{He}$ is an author or co-author of more than 100 publications in journals and proceedings of international conferences. $\mathrm{He}$ is an Associate Editor for Circuits, Systems and Signal Processing and International Journal of Electronics. He is a member of the Editorial Board of IET Circuits, Devices \& Systems and Microelectronics Journal. He holds four Czech national patents. 